\title{
Seasonal changes in sea ice kinematics and deformation in the Pacific sector of the Arctic Ocean in 2018/19
}

\author{
Ruibo Lei $^{1}$, Mario Hoppmann ${ }^{2}$, Bin Cheng ${ }^{3}$, Guangyu Zuo ${ }^{1,4}$, Dawei Gui ${ }^{1,5}$, Qiongqiong Cai ${ }^{6}$, H. Jakob Belter ${ }^{2}$, and \\ Wangxiao Yang ${ }^{4}$ \\ ${ }^{1}$ Key Laboratory for Polar Science of the MNR, Polar Research Institute of China, Shanghai, China \\ ${ }^{2}$ Alfred-Wegener-Institut Helmholtz-Zentrum für Polar- und Meeresforschung, Bremerhaven, Germany \\ ${ }^{3}$ Finnish Meteorological Institute, Helsinki, Finland \\ ${ }^{4}$ College of Electrical and Power Engineering, Taiyuan University of Technology, Taiyuan, China \\ ${ }^{5}$ Chinese Antarctic Center of Surveying and Mapping, Wuhan University, Wuhan, China \\ ${ }^{6}$ National Marine Environmental Forecasting Center of the MNR, Beijing, China
}

Correspondence: Ruibo Lei (leiruibo@pric.org.cn)

Received: 22 July 2020 - Discussion started: 25 August 2020

Revised: 31 December 2020 - Accepted: 3 February 2021 - Published: 12 March 2021

\begin{abstract}
Arctic sea ice kinematics and deformation play significant roles in heat and momentum exchange between the atmosphere and ocean, and at the same time they have profound impacts on biological processes and biogeochemical cycles. However, the mechanisms regulating their changes on seasonal scales and their spatial variability remain poorly understood. Using position data recorded by 32 buoys in the Pacific sector of the Arctic Ocean (PAO), we characterized the spatiotemporal variations in ice kinematics and deformation for autumn-winter 2018/19, during the transition from a melting sea ice regime to a nearly consolidated ice pack. In autumn, the response of the sea ice drift to wind and inertial forcing was stronger in the southern and western PAO compared to the northern and eastern PAO. These spatial heterogeneities gradually weakened from autumn to winter, in line with the seasonal increases in ice concentration and thickness. Correspondingly, ice deformation became much more localized as the sea ice mechanical strength increased, with the area proportion occupied by the strongest (15\%) ice deformation decreasing by about $50 \%$ from autumn to winter. During the freezing season, ice deformation rate in the northern PAO was about 2.5 times higher than in the western PAO and probably related to the higher spatial heterogeneity of oceanic and atmospheric forcing in the north. North-south and east-west gradients in sea ice kinematics and deformation within the PAO, as observed especially during autumn in this study, are likely to become more
\end{abstract}

pronounced in the future as a result of a longer melt season, especially in the western and southern parts.

\section{Introduction}

The Pacific sector of the Arctic Ocean (PAO) includes the Beaufort, Chukchi, and East Siberian seas, as well as the Canadian and Makarov basins. Among all the different sectors of the Arctic Ocean, the PAO exhibited the largest decrease in both seasonal sea ice (Comiso et al., 2017) and multi-year sea ice (MYI) (Serreze and Meier, 2018) in recent decades. These changes are most likely attributed to an enhanced ice-albedo feedback (Steele and Dickinson, 2016), increased Pacific water inflow (Woodgate et al., 2012), and a more pronounced Arctic Dipole (Lei et al., 2016). In the PAO, MYI is mainly distributed north of the Canadian Arctic Archipelago (Lindell and Long, 2016), suggesting a strong east-west gradient in sea ice thickness and strength. In summer, the marginal ice zone (MIZ), defined as the area in which the sea ice concentration is less than $80 \%$, can reach as far north as $80^{\circ} \mathrm{N}$ (Strong and Rigor, 2013); thus the southnorth gradient in sea ice properties in the PAO is expected to be larger compared to other sectors of the Arctic Ocean.

Sea ice deformation typically results from the divergenceconvergence of ice floes and the presence of shear stresses, which can enhance redistribution of ice thickness and/or sea 
ice production by creating leads and ridges (Hutchings and Hibler, 2008; Itkin et al., 2018). Loss of MYI and a decreased ice thickness weaken the Arctic sea ice cover, increase floe mobility (Spreen et al., 2011), and promote ice deformation (Kwok, 2006). Leads forming between ice floes increase heat transfer from the ocean to the atmosphere, a process that is particularly important in winter because of the large temperature gradient (Alam and Curry, 1998). In summer, cracks or leads within the pack ice represent windows that expose the ocean to more sunlight. They may significantly alter many biological processes and biogeochemical cycles, for example supporting under-ice haptophyte algae blooms (Assmy et al., 2017). Under converging conditions, ice blocks are packed randomly during the formation of pressure ridges, creating water-filled voids that act as thermal buffers for subsequent ice growth (Salganik et al., 2020). The high porosity of pressure ridges provides an abundance of nutrients for ice algae communities. As a result, pressure ridges can become biological hotspots (Fernández-Méndez et al., 2018). Thus, accurate characterizations of sea ice deformation are not only relevant to a better understanding of ice dynamics and its role in Arctic climate system but especially also of the evolution of ice-associated ecosystems.

In the PAO, the generally anticyclonic Beaufort Gyre (BG) governs a sea ice motion that is clockwise on average. The boundary and strength of the BG are mainly regulated by the Beaufort High (BH) (Proshutinsky et al., 2009; Lei et al., 2019). An anomalously low BH can result in a reversal of wind and ice motion in the PAO that is normally anticyclonic (Moore et al., 2018). Under a positive Arctic dipole anomaly (DA), more sea ice from the PAO is transported to the Atlantic sector of the Arctic Ocean (AAO), i.e., promoting ice advection from the BG system to the Transpolar Drift Stream (TDS) (Wang et al., 2009). In summer, such a regime would stimulate the ice-albedo feedback and accelerate sea ice retreat in the PAO (Lei et al., 2016). The loss of PAO summer sea ice during the last 4 decades can be explained by an increase in ice advection from the PAO to the AAO by $9.6 \%$ (Bi et al., 2019). In the zonal direction, the enhanced anticyclonic circulation in the PAO, which is majorly related to a positive BH anomaly (Lei et al., 2019), can result in a larger ice advection from the Beaufort and Chukchi Seas to the East Siberian Sea (Ding et al., 2017). The response of sea ice advection in the PAO to interannual variations in atmospheric circulation patterns has been studied extensively (e.g., Vihma et al., 2012), but investigations of ice deformation on a seasonal scale are relatively scarce.

From a dynamical perspective, sea ice consolidation has been characterized using the strength of the inertial signal of sea ice motion (Gimbert et al., 2012), ice-wind speed ratio (IWSR) (Haller et al., 2014), localization, intermittence, and space-time coupling of sea ice deformation (Marsan et al., 2004), as well as the response of ice deformation to wind forcing (Haller et al., 2014). The inertial oscillation is caused by the Earth's rotation and is stimulated by sud- den changes in external forces, mainly due to enhanced wind stress on the ice-ocean interface and surface mixed layer during storms/cyclones or moving fronts of extreme weather events (e.g., Lammert et al., 2009; Gimbert et al., 2012). It is usually weakened by the friction at the ice-ocean interface and internal ice stresses. The localization and intermittence of sea ice deformation indicate the degree of constraint for its spatial range and temporal duration (Rampal et al., 2008). Space-time coupling demonstrates the temporal or spatial dependence of the spatial or temporal scaling laws of ice deformation, which can indicate the brittle behavior of sea ice deformation (Rampal et al., 2008; Marsan and Weiss, 2010). The inertial oscillations of sea ice motion (Gimbert et al., 2012) and the IWSR (Spreen et al., 2011) in the Arctic Ocean have been increasingly associated with reduced sea ice thickness and concentration.

The application of drifting ice buoys to determine the properties and seasonal cycle of the atmosphere, ocean, and sea ice on a basin scale and year-round in Arctic Ocean has been an emerging technique in recent years. For example, drifting buoys are a suitable tool to track relative ice motion. However, the limited presence of such buoys in a given region and season due to financial and logistical constraints has made it difficult so far to accurately distinguish spatial variability and temporal changes in sea ice kinematics and deformation in the PAO. During spring 2003, the deformation of a single lead in the Beaufort Sea was investigated using Global Positioning System (GPS) receivers (Hutchings and Hibler, 2008). Sea ice deformation and its length scaling law in the southern PAO during March-May have been estimated by Hutchings et al. $(2011,2018)$ and Itkin et al. (2017). Based on the dispersion characteristics of ice motion estimated from buoy data recorded in the southern Beaufort Sea, Lukovich et al. (2011) found that the scaling law of absolute zonal dispersion is about twice that in the meridional direction. Lei et al. (2020a, b) used data recorded by two buoy arrays deployed in the northern PAO to describe the influence of cyclonic activities and the summer sea ice regime on the seasonal evolution of sea ice deformation. In addition to in situ buoy data, high-resolution satellite images (e.g., Kwok, 2006) and sea ice numerical models (e.g., Hutter et al., 2018) have been used to identify spatial and temporal variations in ice deformation on a basin scale. RADARSAT data for example revealed that the length scaling law of ice deformation in the western Arctic Ocean increased in summer as the ice pack weakens and internal stresses cannot be transmitted over long distances compared to winter (Stern and Lindsay, 2009). However, an assessment of the ability of satellite techniques to accurately characterize ice deformation, which often occurs on much smaller scales than the image resolution and over much shorter periods than their retrieval interval (Hutchings and Hibler, 2008), still requires more ground-truthing data as provided by drifting buoys. So far, a comprehensive picture of spatial and seasonal variations in sea ice kinematics and deformation for the PAO re- 
gion has not yet been obtained, and our understanding is particularly limited with respect to the transition from the melting season to the winter with a near-rigid-lid consolidated ice pack.

In order to address the knowledge gaps outlined above, 27 drifting buoys were deployed on sea ice in the PAO during August and September 2018 by the Chinese National Arctic Research Expedition (CHINARE) and the TICE expedition led by the Alfred Wegener Institute. In this study, we combined the data measured by these buoys with other available buoy data from the International Arctic Buoy Programme (IABP) to identify the spatial variability of sea ice kinematics and deformation in the PAO from melting to freezing seasons, and we linked these results to the atmospheric forcing responsible for the observed changes in ice dynamics.

\section{Data and methods}

\subsection{Deployment of drifting buoys}

Four types of buoys were used in this study (Fig. 1): the Snow and Ice Mass Balance Array (SIMBA) buoy manufactured by the Scottish Association for Marine Science Research Services Ltd, Oban, Scotland; the Snow Buoy (SB) designed by the Alfred Wegener Institute and manufactured by MetOcean Telematics, Halifax, Canada; the ice Surface Velocity Program drifting buoy (iSVP) also manufactured by MetOcean Telematics; and the ice drifter manufactured by the Taiyuan University of Technology (TUT), China. All buoys were equipped with GPS receivers providing a positioning accuracy of better than $5 \mathrm{~m}$ and regularly reporting to a land-based receiving system using the Iridium satellite network.

During the CHINARE, 9 SIMBA buoys and 11 TUT buoys were deployed in a narrow zonal section of $156-171^{\circ} \mathrm{W}$ and a wide meridional range of $79.2-84.9^{\circ} \mathrm{N}$ in August 2018 (Figs. 1 and 2). This deployment scheme was designed to facilitate the analysis of changes in ice kinematics from the loose MIZ to the consolidated pack ice zone (PIZ). Of these 20 buoys, 15 were deployed in the northern part of the PAO as a cluster within close distance of each other (black circles in Fig. 2) to allow an estimation of ice deformation rates. In addition, data from five SIMBAs and two SBs deployed by the TICE expedition in the Makarov Basin during September 2018 (Figs. 1 and 2) were also used to estimate ice deformation rates. Because the ice thickness at the deployment sites was comparably large (1.22 to $2.49 \mathrm{~m}$ ), the buoys were able to survive into winter and beyond. Position data from one iSVP deployed during the previous CHINARE in 2016 (Lei et al., 2020b) and four other IABP buoys were also included in this study. The IABP buoys were deployed by the British Antarctic Survey or Environment Canada in the east of the PAO during August-September 2018. Here we use the position data from these 32 buoys (Fig. 2) to describe spatial variations in ice kinematics between August 2018 and February 2019. We chose this study period because it represents a transition period during which the mechanical properties of sea ice are expected to change considerably (e.g., Herman and Glowacki, 2012; Hutter et al., 2018). Two-thirds of the buoys (22) continued to send data until or beyond the end of the study period. During this study period, the buoy trajectories during the study period roughly covered the region of $76-87^{\circ} \mathrm{N}$ and $155^{\circ} \mathrm{E}-110^{\circ} \mathrm{W}$, which we define as the study region.

\subsection{Analysis of sea ice kinematic characteristics}

All buoys were configured to a sampling interval of either 0.5 or $1 \mathrm{~h}$. Prior to the calculation of ice drift velocity, position data measured by the buoys were interpolated to a regular interval $(\tau)$ of $1 \mathrm{~h}$. To quantify meridional (zonal) variabilities of ice kinematic properties, we used data from buoys that were within 1 standard deviation of the average longitude (latitude). This constraint helped to minimize the influence of the zonal (meridional) difference on the meridional (zonal) variabilities. The resulting meridional extent for the assessment of the zonal variabilities of ice kinematics ranged from 350 to $402 \mathrm{~km}$, while the zonal extent for the assessment of the meridional variabilities ranged from 195 to $285 \mathrm{~km}$. Their seasonal changes can be considered moderate $(<40 \%)$, although a divergence-convergence of the floes occurred at all times. Using half a standard deviation to constrain the calculation range, there is no essential change in the identified meridional and zonal dependencies of ice kinematics from those obtained using 1 standard deviation. Thus, we consider our evaluation method as robust. Meridional variabilities are related to the transition from the MIZ to the PIZ, while zonal variabilities indicate the change between the region north of the Canadian Arctic Archipelago, where the MYI dominates (Lindell and Long, 2016), and the Makarov Basin, which is mainly covered by seasonal ice (Serreze and Meier, 2018).

Two parameters were used to characterize sea ice kinematics. First, the IWSR was used to investigate the response of the sea ice motion to wind forcing. Impacts of data resampling intervals $(1-48 \mathrm{~h}$ ), meridional and zonal spatial variabilities, intensity of wind forcing, near-surface air temperature, and ice concentration on the IWSR were assessed. These parameters are related to either spatiotemporal changes in atmospheric and sea ice conditions or the frequency distributions of ice and wind speeds. The data used to characterize the atmospheric forcing, including sea level air pressure (SLP), near-surface air temperature at $2 \mathrm{~m}\left(T_{2 \mathrm{~m}}\right)$, and wind velocity at $10 \mathrm{~m}\left(W_{10 \mathrm{~m}}\right)$, were obtained from the ECMWF ERA-Interim reanalysis dataset (Dee et al., 2011). Sea ice concentration was obtained from the Advanced Microwave Scanning Radiometer 2 (AMSR2) (Spreen et al., 2008). To identify the state of the atmospheric forcing and the sea ice conditions relative to the climatology, we also calculated anomalies of SLP, $T_{2} \mathrm{~m}, W_{10 \mathrm{~m}}$, ice concentration, 


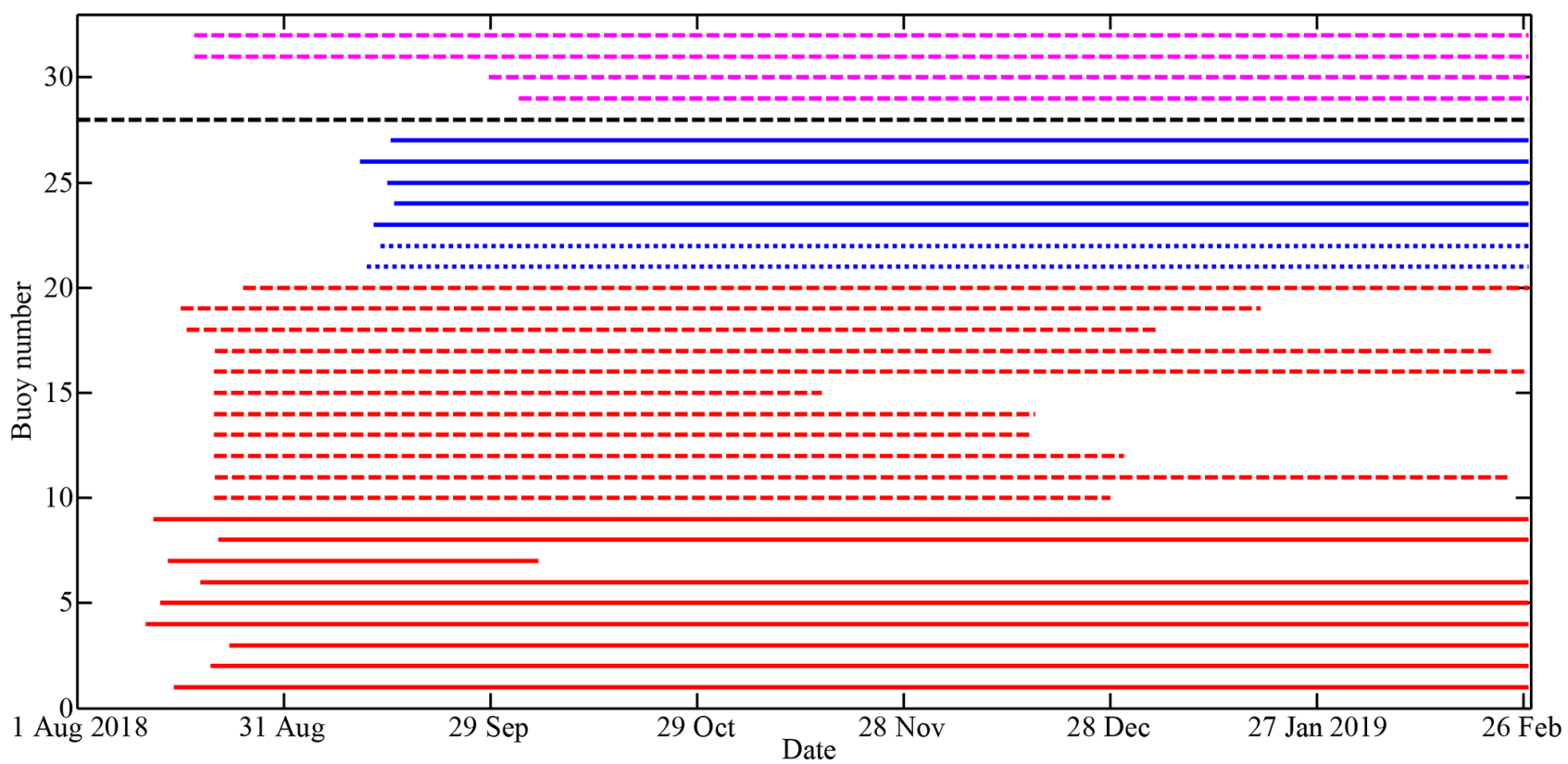

Figure 1. Operational periods of all buoys included in this study. Red lines denote buoys deployed during CHINARE in August 2018; blue lines denote buoys deployed during TICE; the black line indicates the buoy deployed during CHINARE 2016; purple lines represent IABP buoys. Solid, dashed, short-dashed, and dotted-dashed lines denote SIMBA, TUT, SB, and iSVP or other buoys, respectively.

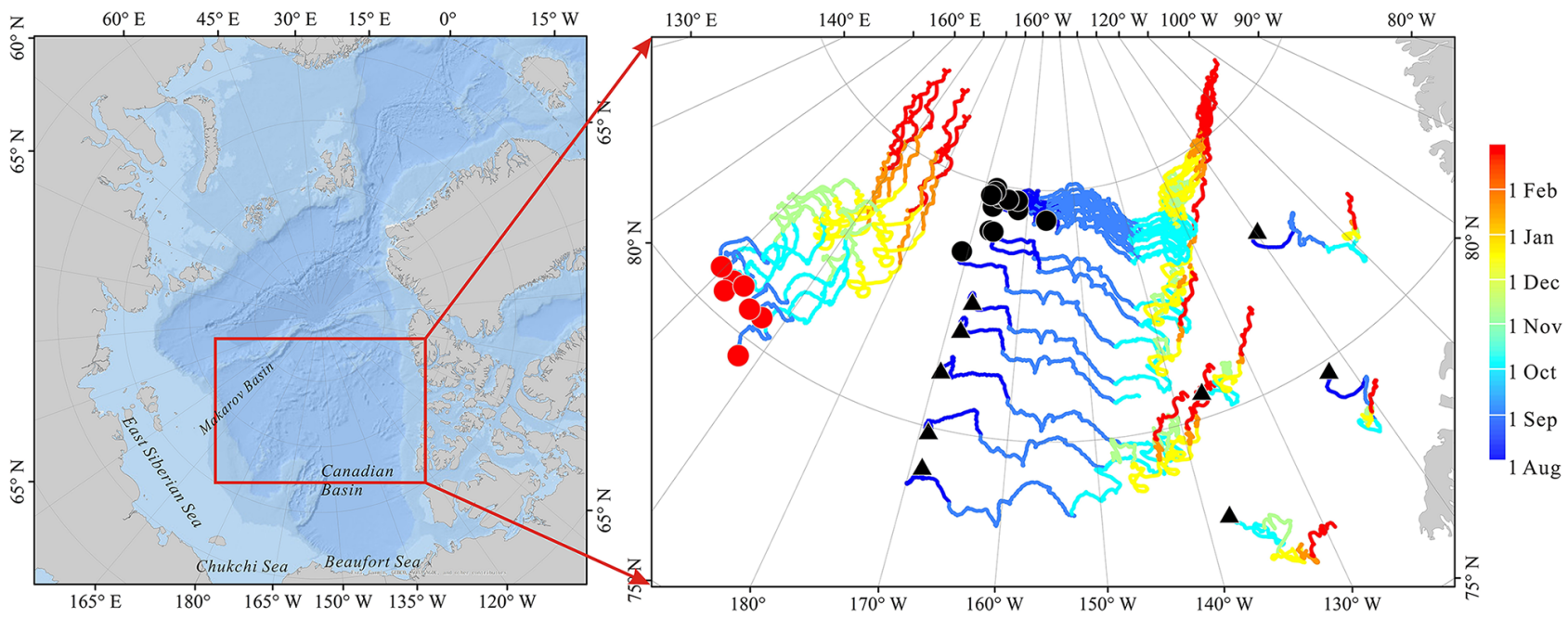

Figure 2. Buoy trajectories between deployment sites (indicated by circles and triangles) and buoy locations on 28 February 2019 . Trajectories from 15 buoys deployed during CHINARE at locations indicated by black circles and 7 buoys deployed during TICE at locations indicated by red circles were used to estimate ice deformation rate. For buoys deployed prior to August 2018, the starting point of the trajectory was set to 1 August 2018.

and ice drift speed relative to the 1979-2018 averages. To estimate ice concentration anomalies, we used ice concentration data from the Nimbus-7 Scanning Multichannel Microwave Radiometer (SMMR) and its successors (SSM/I and SSMIS) (Fetterer et al., 2017) because they cover a longer period compared to the AMSR2 data. We used the daily product of sea ice motion (Tschudi et al., 2019, 2020) provided by the National Snow and Ice Data Center (NSIDC) to es- timate anomalies of ice speed. However, this could only be estimated for August-December 2018 because of the delayed release of NSIDC data.

Second, the inertial motion index (IMI) was used to quantify the inertial component of the ice motion. To obtain the IMI, we applied a fast Fourier transformation to normalized hourly ice velocities. Normalized ice velocities were calculated by scaling the velocity values to monthly averages, al- 
lowing seasonal change to be assessed independently of the magnitudes of ice velocities. The frequency of the inertial oscillation varies with latitude according to

$f_{0}=2 \Omega \sin \theta$,

where $f_{0}$ is the inertial frequency, $\Omega$ is the Earth rotation rate, and $\theta$ is the latitude. $f_{0}$ ranges from 2.01 to 1.94 cycles $\mathrm{d}^{-1}$ between 90 and $75^{\circ} \mathrm{N}$. Rotary spectra calculated from sea ice velocity using complex Fourier analysis were used to identify signals of inertial or tidal origin, both of which have a frequency of $\sim 2$ cycles $^{-1}$ in the Arctic Ocean (Gimbert et al., 2012). According to Gimbert et al. (2012), the complex Fourier transformation $\widehat{U}(\omega)$ is defined as

$\widehat{U}(\omega)=\frac{1}{N} \sum_{t=t_{0}}^{t_{\text {end }}-\Delta t} e^{-i \omega t}\left(u_{x}+i u_{y}\right)$,

where $N$ and $\Delta t$ are the number and temporal interval of velocity samples, $t_{0}$ and $t_{\text {end }}$ are the start and end times of the temporal window, $u_{x}$ and $u_{y}$ are the zonal and meridional ice speeds at $t+0.5 \Delta t$ on an orthogonal geographical grid, and $\omega$ is the angular frequency. The IMI is defined as the amplitude at the negative-phase inertial frequency, i.e., $-f_{0}$, after the complex Fourier transformation. The energies that contributed to the amplitude at $-f_{0}$ comprise the potential contributions from quasi-semidiurnal inertial and tidal oscillations, as well as the high-frequency components of wind and oceanic forcing. Those in the positive phase, $f_{0}$, exclude contributions from the inertial oscillation and only comprise other components compared to that at $-f_{0}$. This is because the spectral peaks associated with the tidal oscillation are roughly symmetric at positive and negative phases as a first-order approximation (Gimbert et al., 2012). On the contrary, the spectral peak associated with the inertial oscillation is asymmetric and only occurs in the negative phase in the Arctic Ocean. Thus, we will identify the seasonal changes in the contributions of the inertial oscillation by comparing the amplitude at the negative-phase quasisemidiurnal frequency, i.e., IMI, to the positive-phase amplitude (PHA). Such a method to separate the inertial oscillation from the tidal oscillation has been used by Lammert et al. (2009), who attempted to identify cyclone-induced inertial ice oscillation in Fram Strait. The background noise originating from high-frequency components of wind and oceanic forcing can slightly shift the local maxima from the targeted frequencies of the IMI and PHA (Geiger and Perovich, 2008). Thus, we identify the local maximum amplitude in the range of $-f_{0} \pm 0.03$ for the IMI and in the range of $2 \pm 0.03$ for the PHA. If no local maximum can be identified within the predefined ranges, we use the amplitudes at $-f_{0}$ and 2 as the IMI and PHA, respectively. Such a situation is encountered in $15 \%$ of the IMI cases and in $95 \%$ of the PHA cases. This implies that the inertial oscillation is much more prevalent, while the tidal oscillation can be ignored regardless of seasons and buoys under consideration.
This result might be related to the fact that, throughout the study period, all the buoys drifted over the deep basins far beyond the continental shelf.

\subsection{Analysis of sea ice deformation characteristics}

Buoy position data were also used to estimate differential kinematic properties (DKPs) of the sea ice deformation field. The DKPs include divergence (div), shear (shr), and total deformation $(D)$ rates of sea ice estimated within the area enclosed by any three buoys, as shown by Itkin et al. (2017). Following Hutchings and Hibler (2008), DKPs were calculated as follows:

$\operatorname{div}=\frac{\partial u}{\partial x}+\frac{\partial v}{\partial y}$,

$\operatorname{shr}=\sqrt{\left(\frac{\partial u}{\partial x}-\frac{\partial v}{\partial y}\right)^{2}+\left(\frac{\partial u}{\partial y}+\frac{\partial v}{\partial x}\right)^{2}}$,

and

$D=\sqrt{\operatorname{div}^{2}+\operatorname{shr}^{2}}$,

where $\frac{\partial u}{\partial x}, \frac{\partial u}{\partial y}, \frac{\partial v}{\partial x}$, and $\frac{\partial v}{\partial y}$ are the strain components on an orthogonal geographical grid. Sea ice strain rate was only estimated for those buoy triangles with internal angles in excess of $15^{\circ}$ and for ice speeds larger than $0.02 \mathrm{~m} \mathrm{~s}^{-1}$ to ensure a high accuracy (Hutchings et al., 2012). Total deformation $D$ was used to characterize the spatial and temporal scaling laws as follows:

$D \propto L^{-\beta}$,

and

$D \propto \tau^{-\alpha}$,

where $L$ is the length scale, $\tau$ is the sampling interval, and $\beta$ and $\alpha$ are spatial and temporal scaling exponents which indicate the decay rates of ice deformation in the spatial or temporal domains. These scaling laws can only indicate the fractal properties of the first moment of ice deformation because of the multi-fractal properties of ice deformation (e.g., Marsan et al., 2004; Hutchings et al., 2011, 2018). To estimate the spatial exponent $\beta$ for the CHINARE buoy cluster, the length scale was divided into three bins of 5-10, 10-20, and $20-40 \mathrm{~km}$ because only a few samples were outside these bins. To estimate the temporal exponent $\alpha$, the position data were resampled to intervals of 1, 2, 4, 8, 12, 24, and $48 \mathrm{~h}$. Because the TICE buoy cluster was mostly $(>70 \%)$ assigned to the $40-80 \mathrm{~km}$ bin, data from this cluster were not suitable for the estimation of the scale effect. A space-time coupling index, $c$, denoting temporal (spatial) dependence of the spatial (temporal) scaling exponent, can be expressed as

$\beta(\tau)=\beta_{0}-c \ln (\tau)$, 
where $\beta_{0}$ is a constant. The areal localization index, $\delta_{15} \%$, was used to quantify the localization of the strongest sea ice deformation, defined as the fractional area accommodating the largest $15 \%$ of the ice deformation in the research domain (Stern and Lindsay, 2009). The $\delta_{15} \%$ was calculated for the $10-20 \mathrm{~km}$ length bin for the CHINARE buoy cluster, since this bin contained more samples to ensure a statistical rationality. To identify the influence of the temporal scale on the localization of ice deformation, all data were resampled to intervals of $1,2,4,8,12,24$, and $48 \mathrm{~h}$.

\subsection{Atmospheric circulation pattern}

We calculated the seasonal Central Arctic Index (CAI) and DA index to relate these large-scale atmospheric circulation patterns to the potential of sea ice advection from the study region to the AAO. Further, we calculated the seasonal AO and $\mathrm{BH}$ indices to relate them to the strength of the BG (Lei et al., 2019). Monthly SLP data north of $70^{\circ} \mathrm{N}$ obtained from the NCEP/NCAR reanalysis I dataset were used to calculate the empirical orthogonal functions (EOFs), with the $\mathrm{AO}$ and DA as the first and second modes of the EOF (Wang et al., 2009). The CAI was defined as the difference in SLP between $90^{\circ} \mathrm{W}$ and $90^{\circ} \mathrm{E}$ at $84^{\circ} \mathrm{N}$ (Vihma et al., 2012). The BH index was calculated as the SLP anomaly over the domain of 75$85^{\circ} \mathrm{N}, 170^{\circ} \mathrm{E}-150^{\circ} \mathrm{W}$ (Moore et al., 2018) relative to $1979-$ 2018 climatology.

\section{Results and discussions}

\subsection{Spatial and seasonal changes in atmospheric and sea ice conditions}

The BH index for autumn (September, October, and November) 2018 was moderate, ranking the 10th highest in 19792018 (Fig. 3a). However, the BH index for the following winter (December, January, and February) was much lower $(-5.6 \mathrm{hPa})$, ranking the fourth lowest in 1979-2018 (Fig. 3b). Both CAI and DA were positive in autumn 2018, but still within 1 standard deviation of the 1979-2018 climatology (Fig. 3c and e). However, both indices were strongly positive in winter 2018/19, ranking the third and second highest in 1979-2018, respectively (Fig. 3d and f). The sea ice in the PAO is expected to be considerably impacted by these seasonal changes in atmospheric circulation patterns as a result of the enhanced northward advection of sea ice to the AAO (e.g., Bi et al., 2019). As an example, a pronounced sea ice reduction has been observed in the Bering Sea in March 2019, where sea ice extent was 70\%-80\% lower than normal (Perovich et al., 2019).

Associated with the seasonal change in the $\mathrm{BH}$ index, there was a distinct contrast in the pattern of the BG from anticyclonic in autumn to cyclonic in winter. Wind vectors and ice drift trajectories during autumn 2018 were generally clockwise, while those during the following winter were counter- clockwise. The latter resulted in all buoys drifting northeastward and integrating into the TDS from December 2018 onward (Fig. 4). In autumn 2018, strong northerly winds only appeared in the northwestern part of study region (Fig. 4a) and were associated with a moderately positive CAI and DA. However, in winter 2018/2019, enhanced northerly winds prevailed almost across the entire study region (Fig. 4b) and were associated with an extremely positive $\mathrm{CAI}$ and $\mathrm{DA}$. The $T_{2 \mathrm{~m}}$ anomalies averaged over the study region were $3.9^{\circ} \mathrm{C}$ in autumn and $0.7^{\circ} \mathrm{C}$ in winter (Fig. $4 \mathrm{c}$ and d), ranking the second and 11th highest in 1979-2018, respectively.

The CHINARE buoys were deployed within a narrow meridional section at about $170^{\circ} \mathrm{W}$. On 20 August 2018, sea ice concentration in this section, and especially in the southern part, was considerably lower than that in the eastern part of the study region at about $120^{\circ} \mathrm{W}$, where other buoys had been deployed (Fig. 5a). Subsequently, ice concentration increased considerably, with almost all buoys being located in the PIZ by 20 September 2018 (Fig. 5b). However, the CHINARE buoys in the south and all TICE buoys remained within $70 \mathrm{~km}$ from the ice edge, which retreated further during August-September 2018. By 20 October 2018, ice concentration surrounding all buoys had increased to over $95 \%$ (Fig. 5c).

In September and early October 2018, ice concentrations were considerably lower than the 1979-2018 average. Ice concentrations increased after early October and became comparable with climatological values (Figs. $6 \mathrm{~b}$ and $7 \mathrm{~b}$ ). In October 2018, ice concentration was much lower in the southern and western parts of the study region compared to the north and east. Subsequently, the spatial gradient of sea ice concentration gradually decreased. Compared to the 1979-2018 climatology, wind speed was lower throughout most of the study period except for episodic increases as a result of intrusions of low-pressure systems (Figs. 6c and 7c). In September 2018, ice speed in the south was higher compared to the north (Fig. 6d), suggesting that the sea ice response to wind forcing was stronger in the south because of the lower ice concentration. From October 2018 onwards, this north-south difference gradually disappeared. The study region was dominated by a low SLP during December 2018 and February 2019, which was related to an anomalously low $\mathrm{BH}$ index and subsequent increases in both wind and ice drift speeds (Figs. 6c, d, 7c, d).

\subsection{Spatial and seasonal changes in sea ice kinematic characteristics}

Temporal resampling has little effect on wind speed. However, applying longer resampling intervals to buoy position data may filter out ice motions that occur at higher frequencies (Haller et al., 2014), resulting in reduced ice speed and IWSR (Fig. 8). For example, ice drift speed and IWSR in September 2018 were $0.13 \mathrm{~m} \mathrm{~s}^{-1}$ and 0.027 at a resampling interval of $1 \mathrm{~h}$, and they decreased to $0.01 \mathrm{~m} \mathrm{~s}^{-1}$ and 0.021 

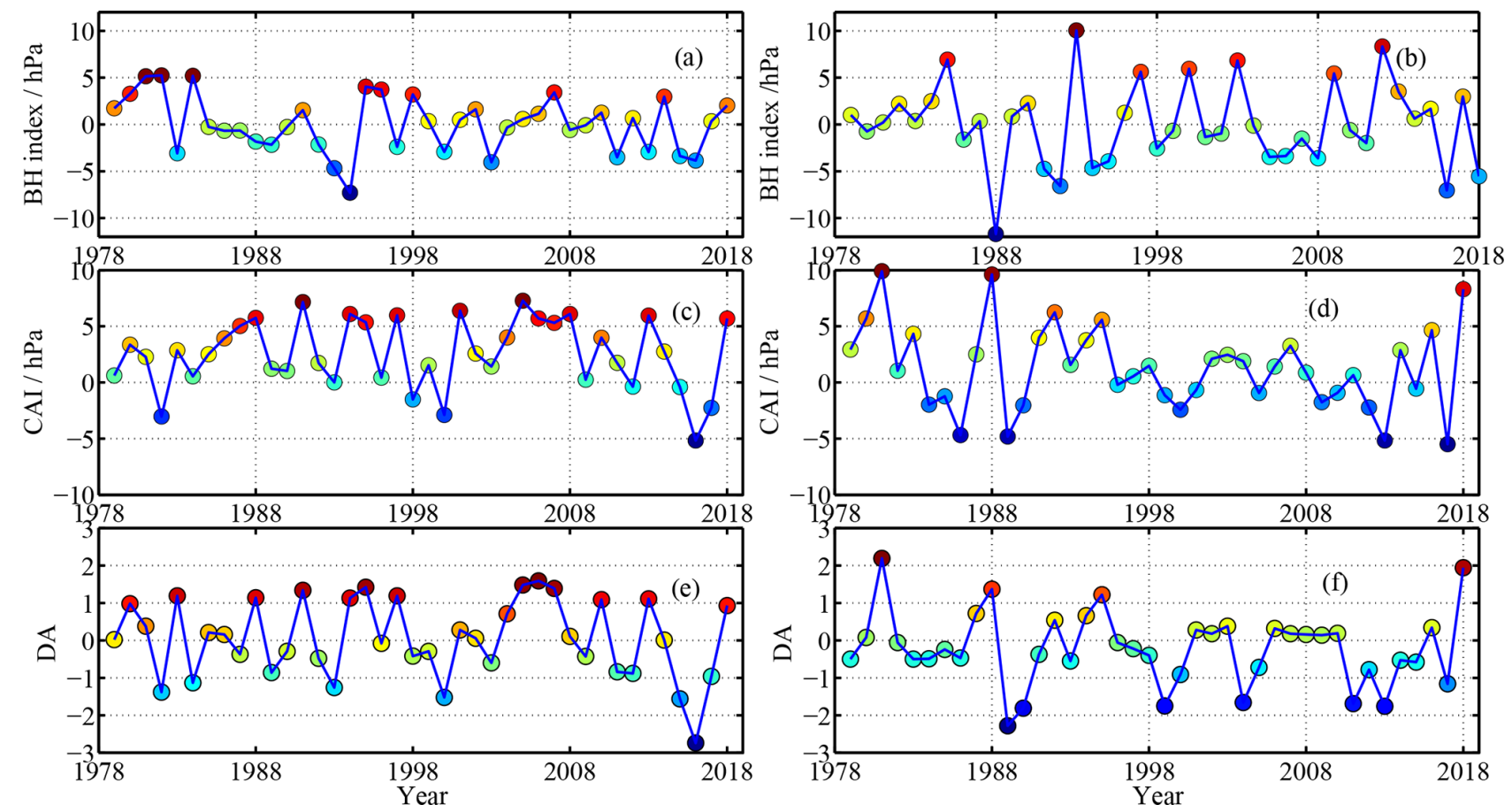

Figure 3. Changes in (a) autumn (SON) and (b) winter (DJF) BH index, (c) autumn and (d) winter CAI, and (e) autumn and (f) winter DA from 1979 to 2018 .

at a resampling interval of $48 \mathrm{~h}$. Both ice speed and IWSR decreased considerably from September to November 2018; afterwards, both variables remained low until the end of the study period. At a resampling interval of $6 \mathrm{~h}$, the IWSR was 0.026 in September 2018 (Fig. 8), which is much higher than that $(0.013)$ obtained in the region close to the North Pole in the same month of 2007 (Haller et al., 2014) because most parts of our study region included the MIZ at that time. This value decreased to $0.008-0.015$ from November to February (Fig. 8), which is comparable to those obtained from the regions north of Siberia or Greenland and the region close to the North Pole during the freezing season, but much smaller than that obtained in Fram Strait (Haller et al., 2014). This implies that, during the freezing season, the response of the sea ice to wind forcing is relatively uniform for the entire Arctic Ocean except for the regions close to Fram Strait where ice speeds markedly increase. In January 2019, a more consolidated ice pack and a relatively weak wind forcing led to both ice drift speed and IWSR reaching minima for the entire study period (Figs. 6c and 7c). The influence of resampling on the IWSR was reduced considerably during the freezing season, implying significant reductions of meandering and sub-daily oscillations in ice motion compared to the melt season. The ratio between IWSRs at 1 and $48 \mathrm{~h}$ intervals in October was $70 \%$ of that in September and remained almost unchanged between November and February.

Factors regulating the IWSR are summarized in Table 1. The impact of the geographical location was significant in autumn, with relatively high IWSRs in the southern or western parts of the study region. However, meridional changes in the IWSR became very small in January-February because the north-south gradient in ice conditions was negligible by that time. The west-east gradient was more pronounced, with a significant relationship between longitude and IWSR throughout the study period. This is consistent with the results given by Lukovich et al. (2011), who identified that the west-east gradient of sea ice kinematics is larger than that in the north-south direction for the southern PAO during the freezing season. In summer and early autumn, the consolidation of the ice field is low, and interactions between individual ice floes approximate rigid particle collisions (Lewis and Richter-Menge, 1998). Thus, in August-October 2018, a lower IWSR is related to stronger wind forcing that enhanced the interactions between floes, leading to a significant negative statistical correlation between the IWSR and wind speed. Similarly, based on the data obtained from the buoys deployed in the TDS region, Haller et al. (2014) also identified that some spikes of the IWSR tend to be associated with a low wind speed. Consolidation of the ice field between November and February 2018 led to reduced ice motion and weaker sea ice response to wind forcing. Thereby, impact of wind forcing on IWSR was insignificant from November onwards. Variations in $T_{2} \mathrm{~m}$ across the study region between 20 August and 30 September 2018 were relatively small $\left(-1.7\right.$ to $\left.-3.5^{\circ} \mathrm{C}\right)$ because of the thermodynamic balance between the sea ice and the atmosphere during the melt 
(a)
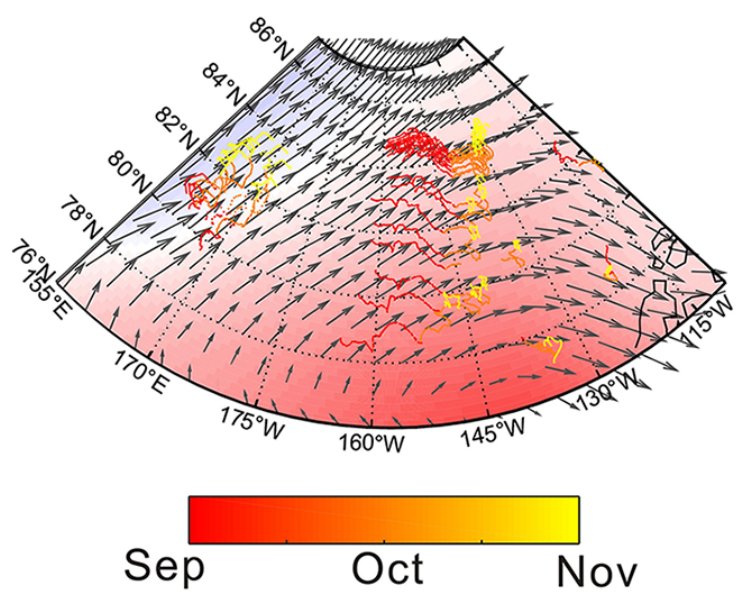

(b)

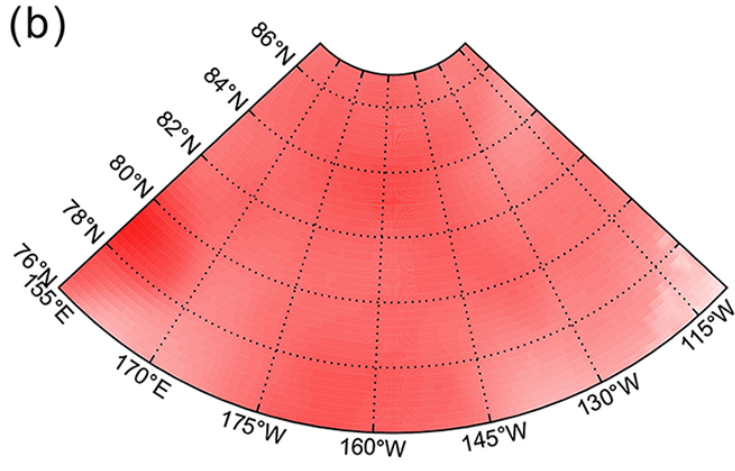

(c)
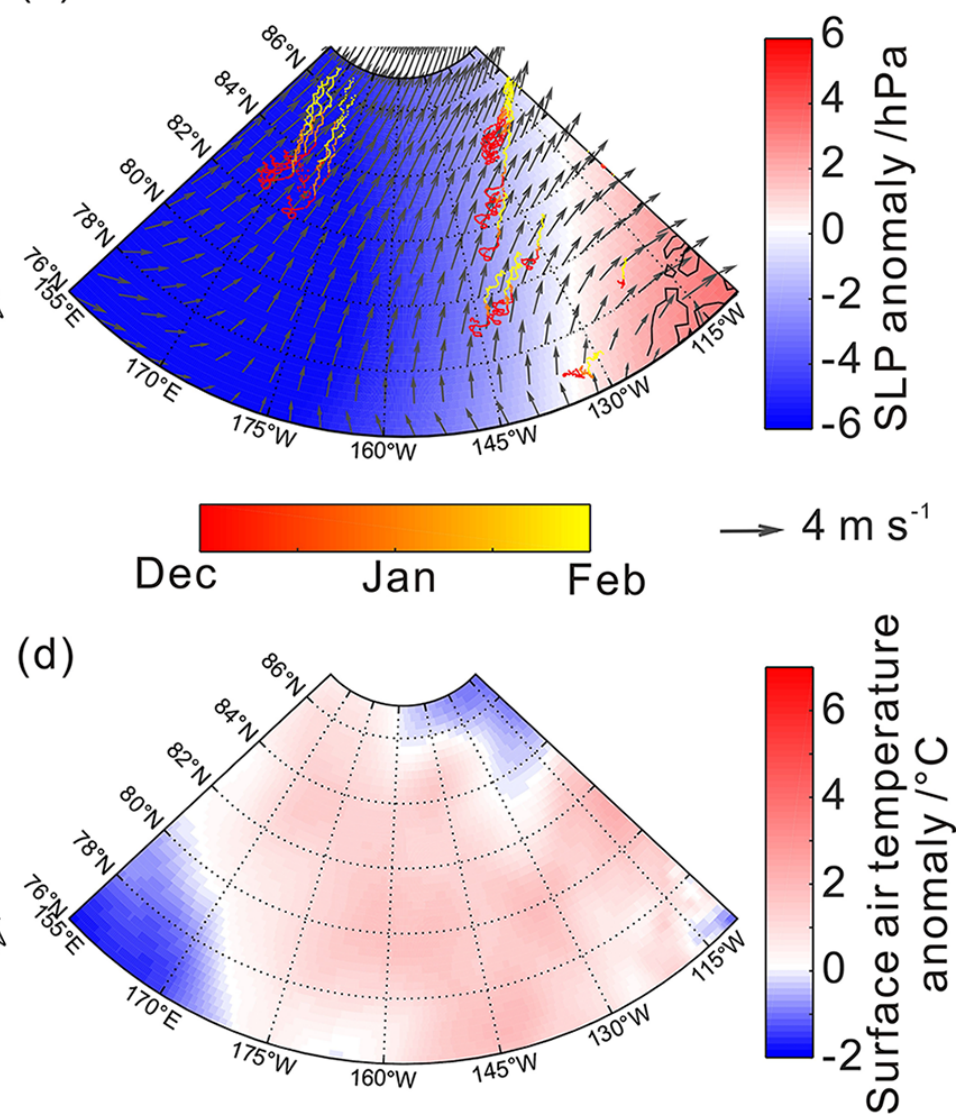

Figure 4. Anomalies of (a, c) SLP and (b, d) near-surface air temperature ( $2 \mathrm{~m})$ over the PAO during (a, b) autumn 2018 and (c, d) winter 2018/19 relative to 1979-2018 climatology; (a, c) arrows indicate seasonal average wind vectors, and colored lines indicate buoy trajectories through time.

Table 1. Statistical relationships between IWSR and selected parameters. Significance levels are $P<0.001(* * *), P<0.01(* *)$, and $P<0.05\left(^{*}\right)$, and n.s. denotes insignificant at the 0.05 confidence level. Numbers in parentheses indicate number of buoys used for the statistics.

\begin{tabular}{lllll}
\hline Month & IWSR vs. lat. & IWSR vs. long. & IWSR vs. $W_{10 \mathrm{~m}}$ & IWSR vs. $T_{2 \mathrm{~m}}$ \\
\hline 20 Aug-30 Sep & $-0.647 * *(24)$ & $-0.738^{* * *}(29)$ & $-0.542^{* *}(32)$ & n.s. \\
Oct & $-0.811^{* * *}(24)$ & $-0.885^{* * *}(29)$ & $-0.866^{* * *}(32)$ & $0.657 * * *(32)$ \\
Nov & $-0.777^{* * *}(23)$ & $-0.765^{* * *}(28)$ & n.s. & $0.736 * * *(32)$ \\
Dec & $-0.736 * * *(22)$ & $-0.829 * * *(27)$ & n.s. & $0.675^{* * *(32)}$ \\
Jan & n.s. & $-0.711^{* *}(23)$ & n.s. & n.s. \\
Feb & n.s. & $-0.610^{* *}(23)$ & n.s. & n.s. \\
\hline
\end{tabular}

season (e.g., Screen and Simmonds, 2010). The statistical relationship between $T_{2 \mathrm{~m}}$ and the IWSR was insignificant during this period. On the contrary, the relationship became significant during October-December 2018, with a higher $T_{2} \mathrm{~m}$ being associated with a larger IWSR because warmer conditions may have weakened ice pack (e.g., Oikkonen et al., 2017). As the continuing thickening of the ice cover further reduced the influence of air temperature on ice kinematics, the statistical relationship between $T_{2 \mathrm{~m}}$ and the IWSR was insignificant in January and February 2019.

The initial strength of the inertial oscillation mainly depends on the wind stress. However, the sustainability of the inertial oscillation is restricted by the internal friction within the Ekman layer in regions with low ice concentration and much open water, or by the ice internal stress in the PIZ (Gimbert et al., 2012). Thus, the inertial component of ice motion is closely associated with the seasonal and spatial 


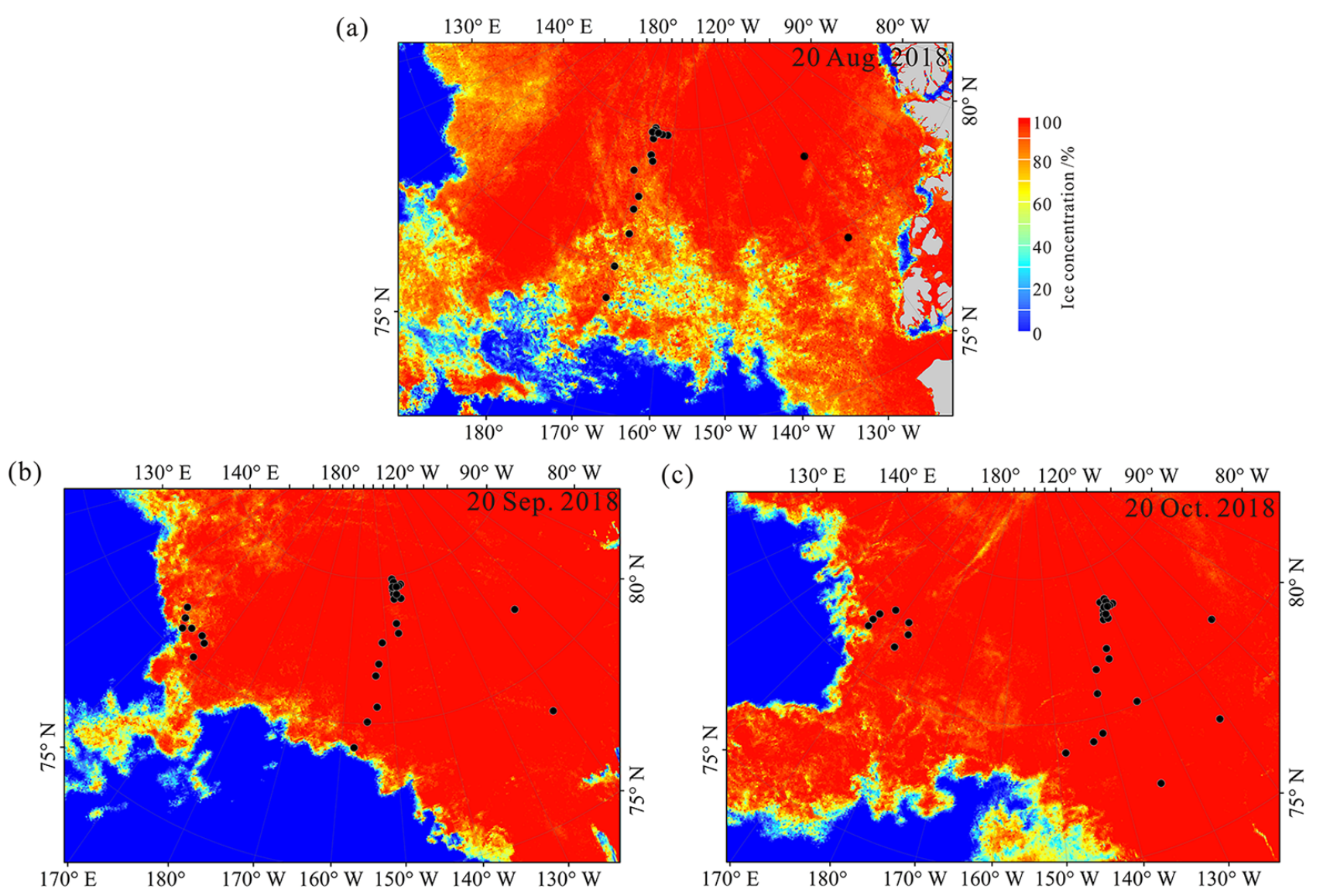

Figure 5. Sea ice concentration across the PAO on (a) 20 August, (b) 20 September, and (c) 20 October 2018, with black dots denoting buoy positions on the given days.

changes in ice conditions. Figure 9 shows monthly IMI and PHA obtained from each buoy displayed at the midpoint of the buoy's trajectory for various months. The combined average monthly IMI of all buoys was $0.099 \pm 0.088$ for the entire study period, with the average for September $2018(0.227)$ being considerably higher. The monthly average IMIs from all buoys decreased from 0.136 in October 2018 to 0.037 in February 2019. Spatial variability of the IMI had almost disappeared by February 2019; the IMI standard deviation in February 2019 was $13 \%-22 \%$ of that in SeptemberOctober 2018. Both the magnitude and the spatiotemporal variations in the PHA were much smaller than those of the IMI. The monthly average PHA of all available buoys during the entire study period was only $18 \%$ of the IMI. The monthly ratio between the PHA and IMI ranged from 0.06 in September 2018 to 0.46 in February 2019. The seasonal damping of this ratio is mainly due to the decrease in the IMI because no statistically significant trend can be identified for the PHA. The standard deviation of the IMI revealed a significant decreasing trend $(P<0.01)$ from $0.069-0.117$ in September-October 2018 to 0.015 in February 2019, which suggests that the spatial variation in the IMI gradually decreased as the winter approached. Similar to the ratio be- tween the absolute magnitudes, the ratio between the standard deviations of the PHA and IMI increased from 0.08 in September to $0.50-0.70$ in January-February. The seasonal increase in this ratio was also mainly due to the decrease in the standard deviation of the IMI. From comparisons between the seasonalities of the IMI and PHA, we infer that the seasonal changes and spatial variations in the IMI could be mainly related to the changes in the inertial oscillation, and the contributions of the tidal oscillation can be ignored throughout the study period.

To eliminate the influence of large-scale spatial variability, we inspected subsets of data obtained from the buoys that were deployed in clusters. The IMI obtained from the CHINARE buoy cluster (black circles in Fig. 2) decreased markedly from 0.223 to 0.081 during SeptemberOctober 2018. However, a similar change was observed 1 month later in October-November 2018 for the TICE buoy cluster. During the freezing season from November to February, the IMI gradually decreased to 0.038 for the CHINARE cluster and to 0.035 for the TICE cluster. Sea ice growth rates of the thin ice in the MIZ in the western and southern PAO are expected to be higher than that in the PIZ in the northern and the eastern PAO (e.g., Kwok and Cunningham, 2008). 

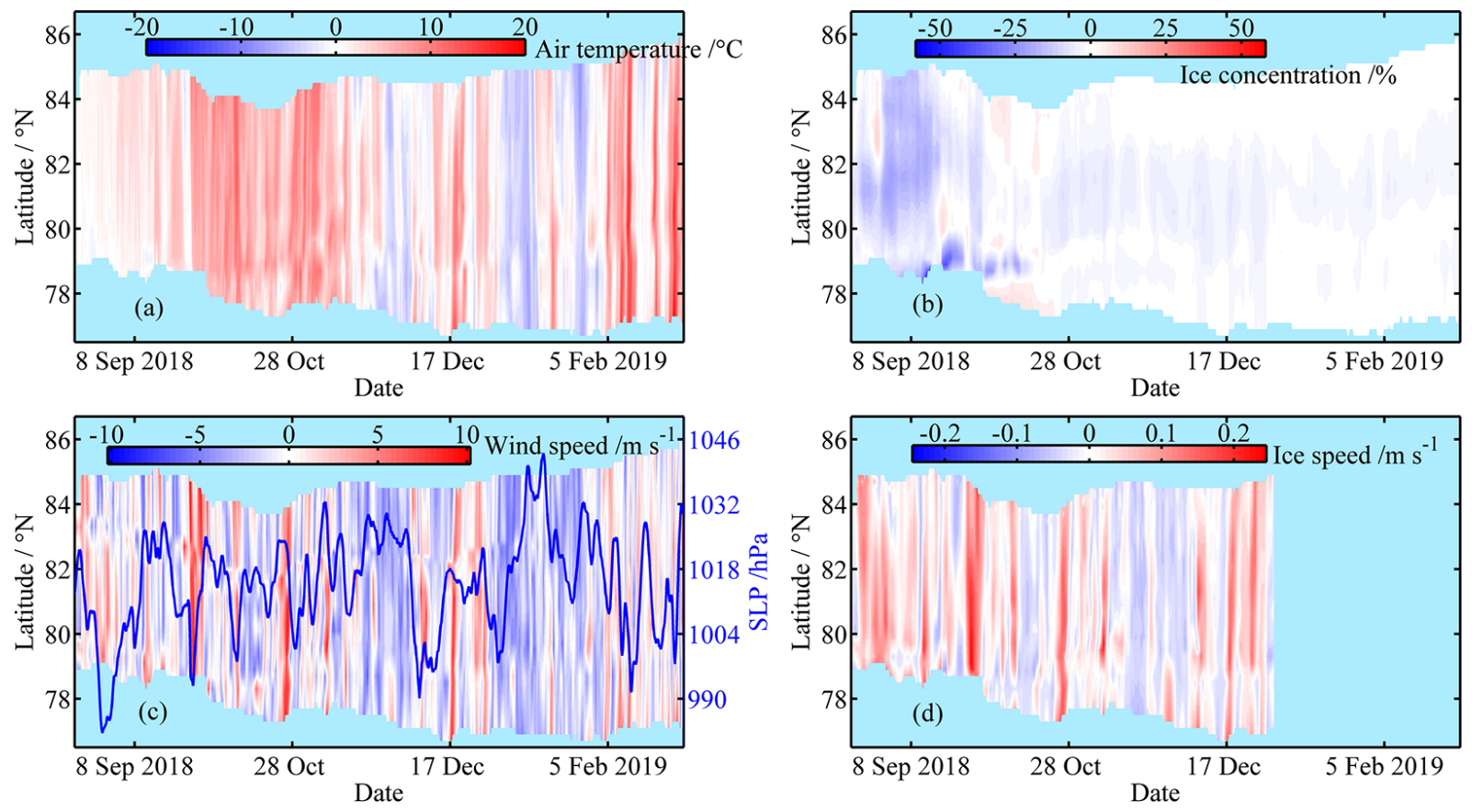

Figure 6. Meridional and temporal changes in anomalies of (a) $T_{2 \mathrm{~m}}$, (b) ice concentration, (c) wind speed, and (d) ice speed in the ice season 2018/19 relative to 1979-2018 climatology; (c) the blue line indicates SLP averaged over the study region.
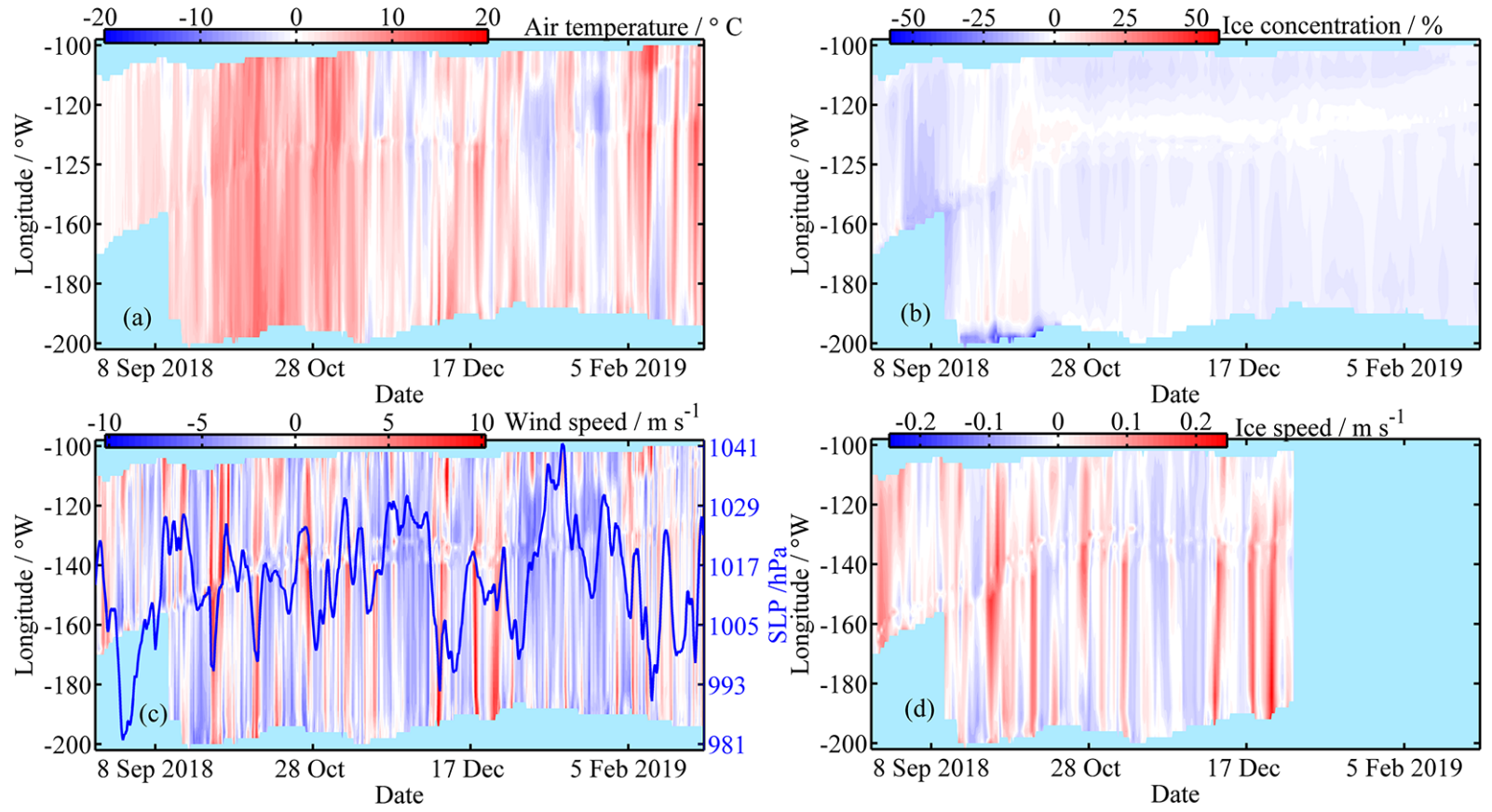

Figure 7. Same as Fig. 2, but for zonal changes. Longitudes with values below -180 denote the eastern Arctic.

Accordingly, the spatial variability of the ice inertial oscillation observed in early autumn gradually disappeared.

To study the temporal changes in the IMI and PHA in more detail, we used a complex Fourier transformation to obtain time series of the IMI and PHA based on a $5 \mathrm{~d}$ tempo- ral window. Here, we only show selected results from three representative buoys for comparison (Fig. 10). Those buoys were initially located in the southernmost and northernmost domain of the CHINARE cluster and in the southernmost domain of the TICE cluster (Fig. 2). The timing of the dis- 

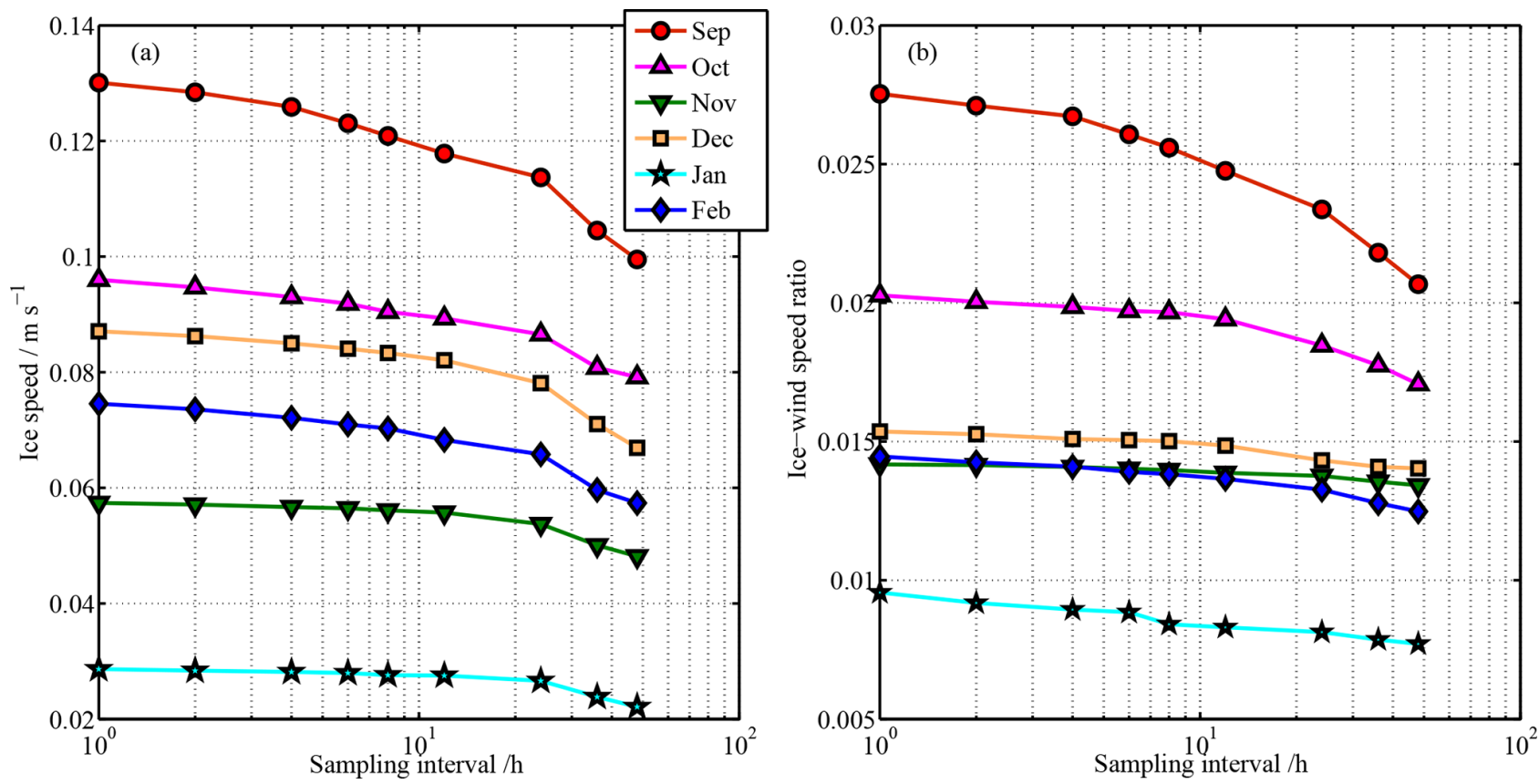

Figure 8. Changes in (a) ice speed and (b) IWSR as a function of position data resampling interval for various months in $2018 / 19$.
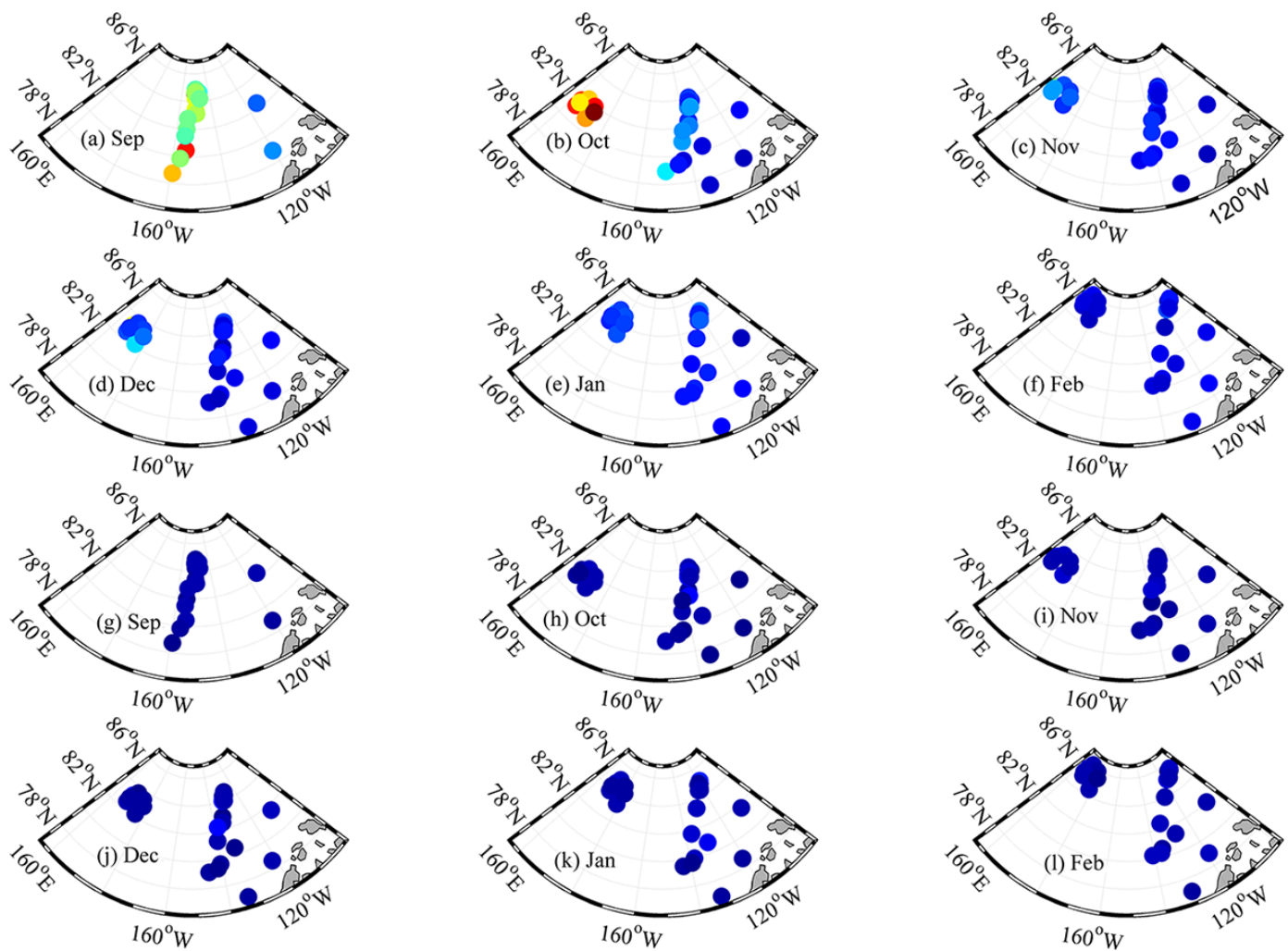

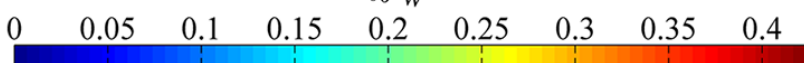

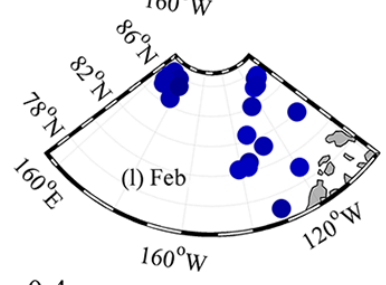

Figure 9. Amplitudes after Fourier transformation of monthly time series of normalized ice velocity at the negative-phase inertial frequency (a-f) and positive-phase semidiurnal frequency (g-l) from September 2018 to February 2019. 

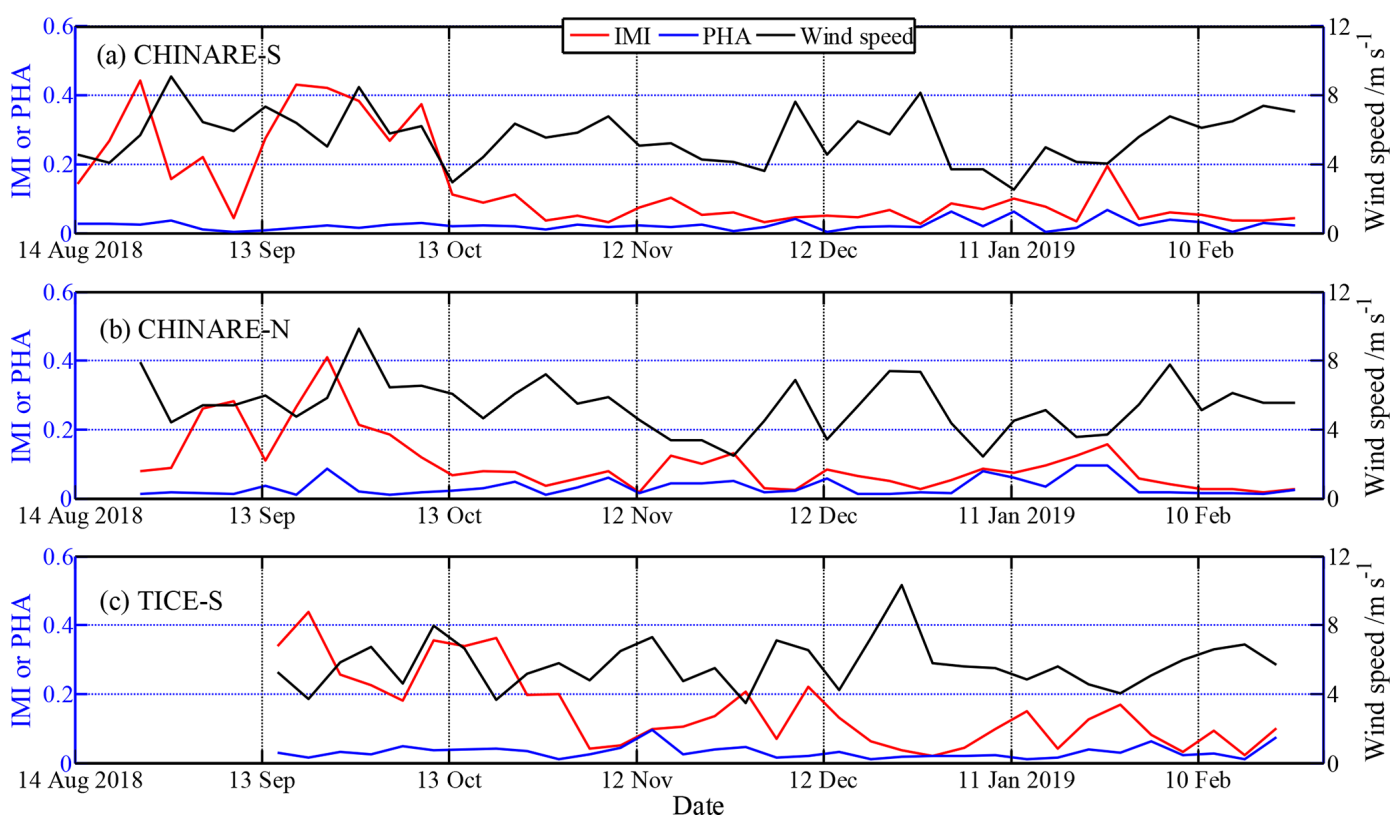

Figure 10. Amplitudes after Fourier transformation of normalized ice velocity at the negative-phase inertial frequency (IMI) and positivephase semidiurnal frequency (PHA) obtained from the $5 \mathrm{~d}$ temporal window, as well as the corresponding wind speed.

tinct seasonal attenuation of the IMI was different between the buoys, occurring in mid-October, late September, and late October 2018 for the CHINARE southernmost and northernmost buoys and the TICE southernmost buoy, respectively (Fig. 10). During the freezing season, the IMI remained at a low level but was still always larger than the PHA. The magnitude of the IMI was mainly regulated by wind forcing during the freezing season. The wind speed can significantly explain the magnitude of the IMI in NovemberFebruary by $22 \%(P<0.05), 45 \%(P<0.001)$, and $21 \%$ $(P<0.05)$ for the CHINARE southernmost and northernmost buoys and the TICE southernmost buoy, respectively. The relatively large wind speed is related to a relatively low IMI because the enhanced wind forcing might increase the ice internal stress and reduce the response of ice motion to inertia forcing. This mechanism is most obvious in the northern PIZ because of the relatively large ice internal stress.

\subsection{Spatial and seasonal changes in sea ice deformation}

For all buoy triangles that were used to estimate ice deformation, the ice concentration within the CHINARE buoy cluster increased most rapidly during late August and early September 2018, and it remained close to $100 \%$ from then onwards (Fig. 11a). A comparable seasonal increase in ice concentration was observed within the TICE buoy cluster 1 month later. To facilitate a direct comparison of the data obtained by the two different buoy clusters, we estimated the ice deformation rate of the TICE buoy cluster at the $10-20 \mathrm{~km}$ scale using the value at the $40-80 \mathrm{~km}$ scale and a constant spatial scaling exponent of 0.55 . The scaling exponent of 0.55 is a seasonal average obtained from the CHINARE buoy cluster. A change of the scaling exponent by $10 \%$ would lead to an uncertainty of about 0.03 for the ice deformation rate. Thus, a constant scaling exponent can be considered acceptable for a study of seasonal variation. In early and midSeptember 2018, the ice deformation rate was low for the CHINARE cluster (Fig. 11b) because of low and relatively stable wind forcing (Fig. 2). For the TICE cluster, both ice deformation rate and ratio between ice deformation rate and wind speed decreased rapidly between 20 September and 10 November 2018, associated with a consolidation of the ice field as ice concentration and thickness increased and ice temperature decreased. However, over the same period, the ice deformation rate obtained by the CHINARE buoy cluster decreased only slightly, which is likely linked to its relatively low initial deformation rate in late September 2018 and to the higher ice concentration (by $15 \%-20 \%$ ) compared to the TICE region.

For the CHINARE buoy cluster, the daily wind speed can explain $35 \%(P<0.001)$ of the daily ice deformation rate estimated from hourly position data throughout the study period. However, for the TICE cluster, changes in ice deformation were mainly regulated by the seasonal evolution of ice concentration between September and early November 2018. The relationship between ice deformation rate and wind speed was insignificant at the statistical confidence level of 0.05 during this period. The ice field had sufficiently consolidated by mid-November 2018, and the relationship between daily ice deformation rate and daily wind speed changed to significant $\left(R^{2}=0.12, P<0.01\right)$ from then onwards. 

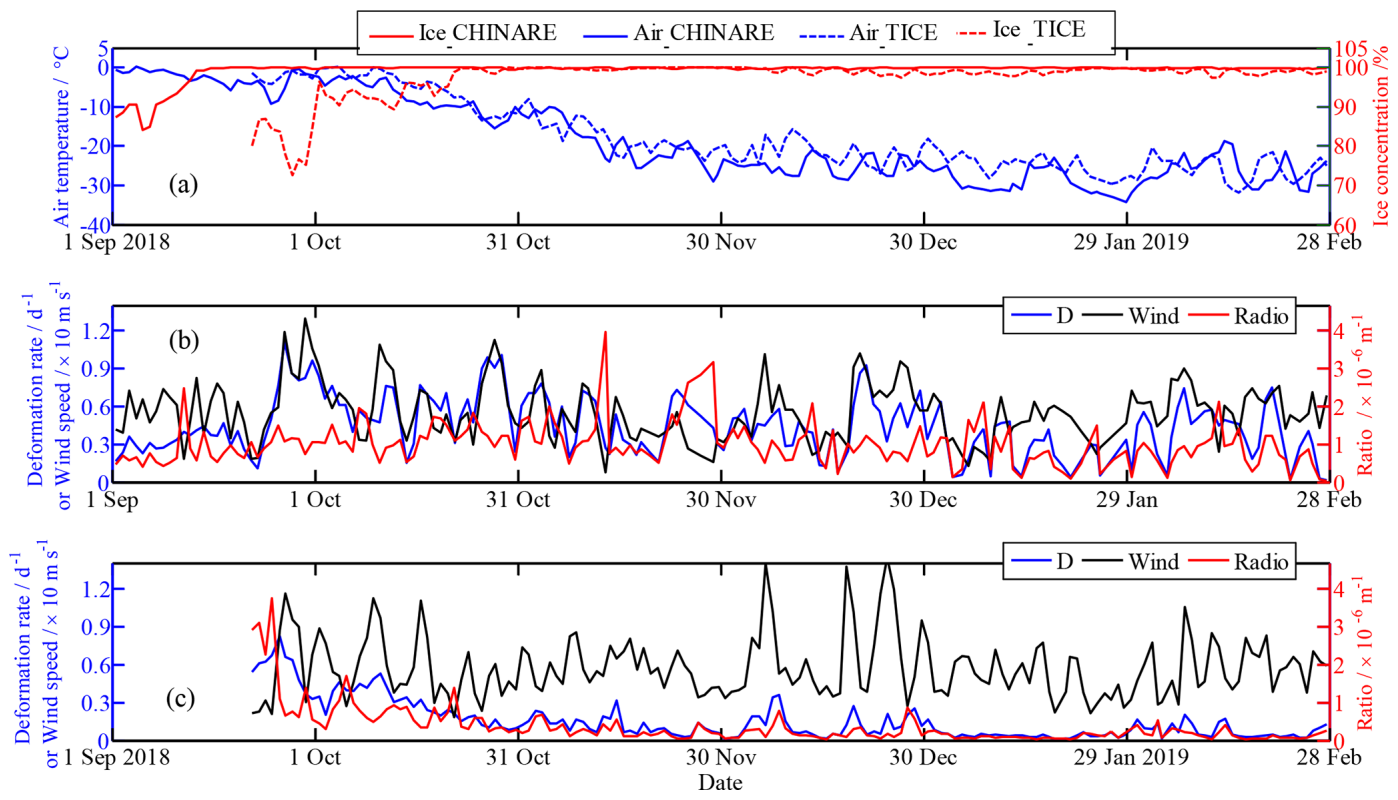

Figure 11. (a) Time series of daily average near-surface $(2 \mathrm{~m})$ air temperature and ice concentration within the CHINARE and TICE buoy clusters. Ice deformation rate $(D)$, wind speed, and their ratio at the 10-20 km scale for the (b) CHINARE and (c) TICE buoy clusters.

The average ratio of ice deformation rate to wind speed in autumn was $1.15 \times 10^{-6} \mathrm{~m}^{-1}$ for the CHINARE cluster and $0.62 \times 10^{-6} \mathrm{~m}^{-1}$ for the TICE cluster; the ratio in winter decreased to $0.86 \times 10^{-6}$ and $0.17 \times 10^{-6} \mathrm{~m}^{-1}$, respectively. This seasonal pattern is consistent with the results given by Spreen et al. (2017), who used the RADARSAT geophysical processor system (RGPS) data to reveal that the annual maximum ice deformation rate occurred in August and decreased gradually to the annual minimum in March. Except for late September 2018, when the ice concentration in the TICE cluster was less than $85 \%$, the ice deformation rate from the CHINARE cluster was generally larger than that of the TICE cluster, with average values of 0.45 and $0.13 \mathrm{~d}^{-1}$, respectively, for October 2018 to February 2019. Sea ice in the region of the TICE cluster was generally thinner compared to the region of the CHINARE cluster. Thus, the difference in ice deformation rate cannot be absolutely explained by a difference in ice conditions between the two regions and is most likely also related to the spatial heterogeneity of wind and/or oceanic forcing. Changes in the direction of wind vectors were more frequent around the CHINARE cluster than around the TICE cluster. Frequent changes in ice drift direction lead to larger ice deformation events, such as those on 11 October and 11 and 26 November 2018 for the CHINARE cluster as shown in Fig. 11b. The drifting trajectories of the TICE cluster were much straighter than those of the CHINARE cluster. Since the CHINARE cluster was located in the core region of the BG, the vorticity of the surface current must be greater than that in the TICE cluster, located at the western boundary of the BG (Armitage et al., 2017).
As a result, ice deformation rate and its ratio to wind speed were lower for the TICE cluster.

Ice deformation rates obtained from the CHINARE buoy cluster at three representative lengths of 7.5, 15, and $30 \mathrm{~km}$ were estimated using Eq. (6). Figure 12 shows that the monthly average ice deformation decreased as the length scale and resampling interval increased, implying an ice deformation localization and intermittency. The ice deformation decreased rapidly at all spatial and temporal scales during the seasonal transition period of September-October and remained low from then onwards. Ice deformation rate obtained using hourly position data from the CHINARE buoy cluster in September 2018 was $0.38 \mathrm{~d}^{-1}$ at the length scale of $30 \mathrm{~km}$, which is comparable to that in September 2016 $\left(0.31 \mathrm{~d}^{-1}\right)$ and much larger than that in September 2014 $\left(0.18 \mathrm{~d}^{-1}\right)$ also observed in northern PAO (Lei et al., 2020a). These observed differences can be related to the strong storms in late September 2018 (Fig. 11b) and early September 2016 (Lei et al., 2020a), in contrast to the relatively stable synoptic conditions and relatively compact ice conditions in September 2014 (Lei et al., 2020a).

Accordingly, the spatial scaling exponent $\beta$ estimated from hourly position data was 0.61 in September 2018, which is comparable to $\beta$ from September 2016 (0.60), but slightly larger than in September 2014 (0.46) observed in northern PAO (Lei et al., 2020a). $\beta$ decreased markedly from September to October 2018 and varied little from then onwards (Fig. 13). With increases in ice thickness and concentration as well as a cooling of the ice cover from October onwards, the consolidation of the ice field is enhanced, and sea ice deformation can spread over longer distances. By Febru- 


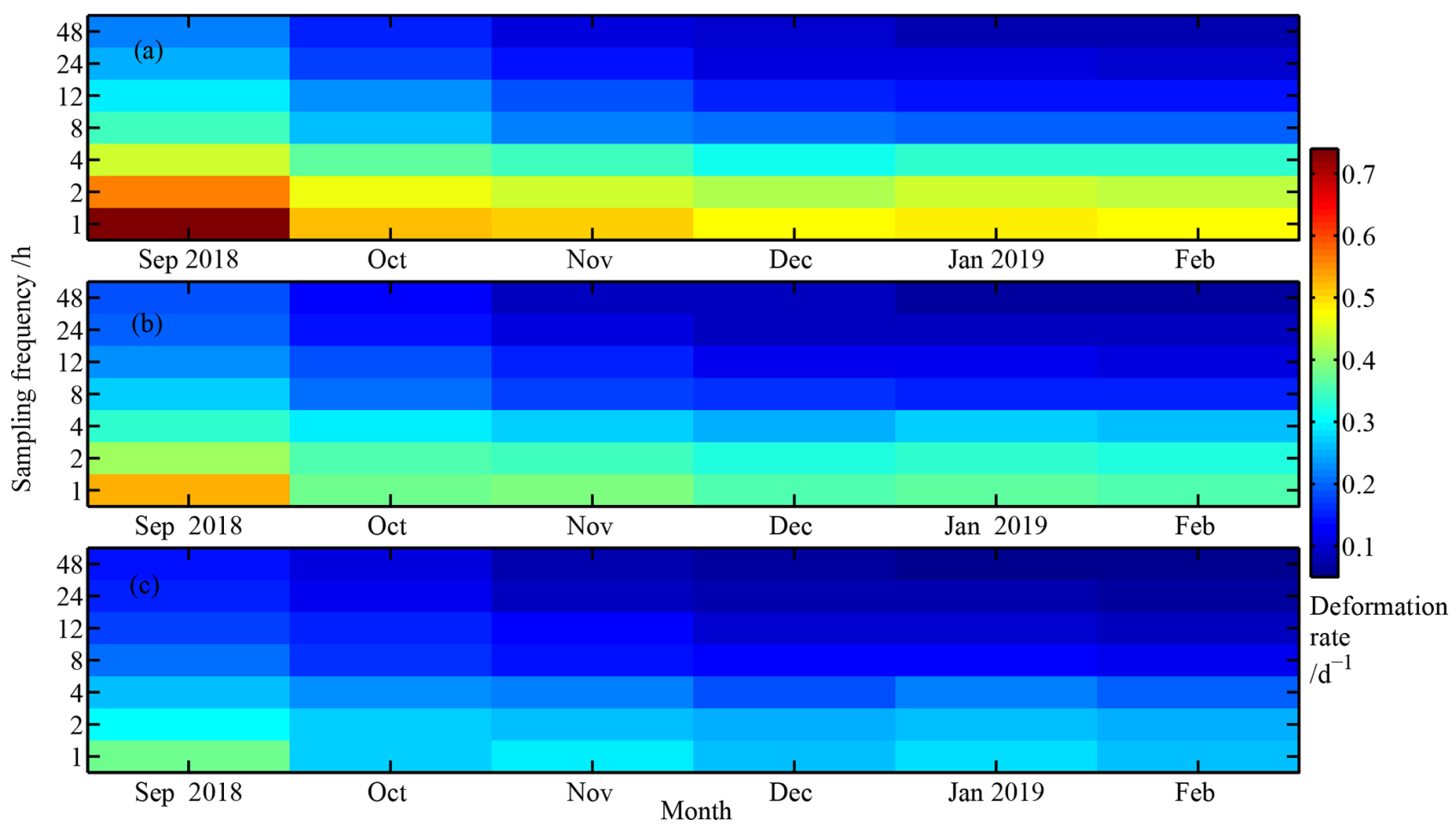

Figure 12. Monthly average sea ice deformation rate calculated from the CHINARE buoy cluster at length scales of (a) $7.5 \mathrm{~km}$, (b) $15 \mathrm{~km}$, and (c) $30 \mathrm{~km}$ using position data resampled at various intervals between 1 and $48 \mathrm{~h}$.

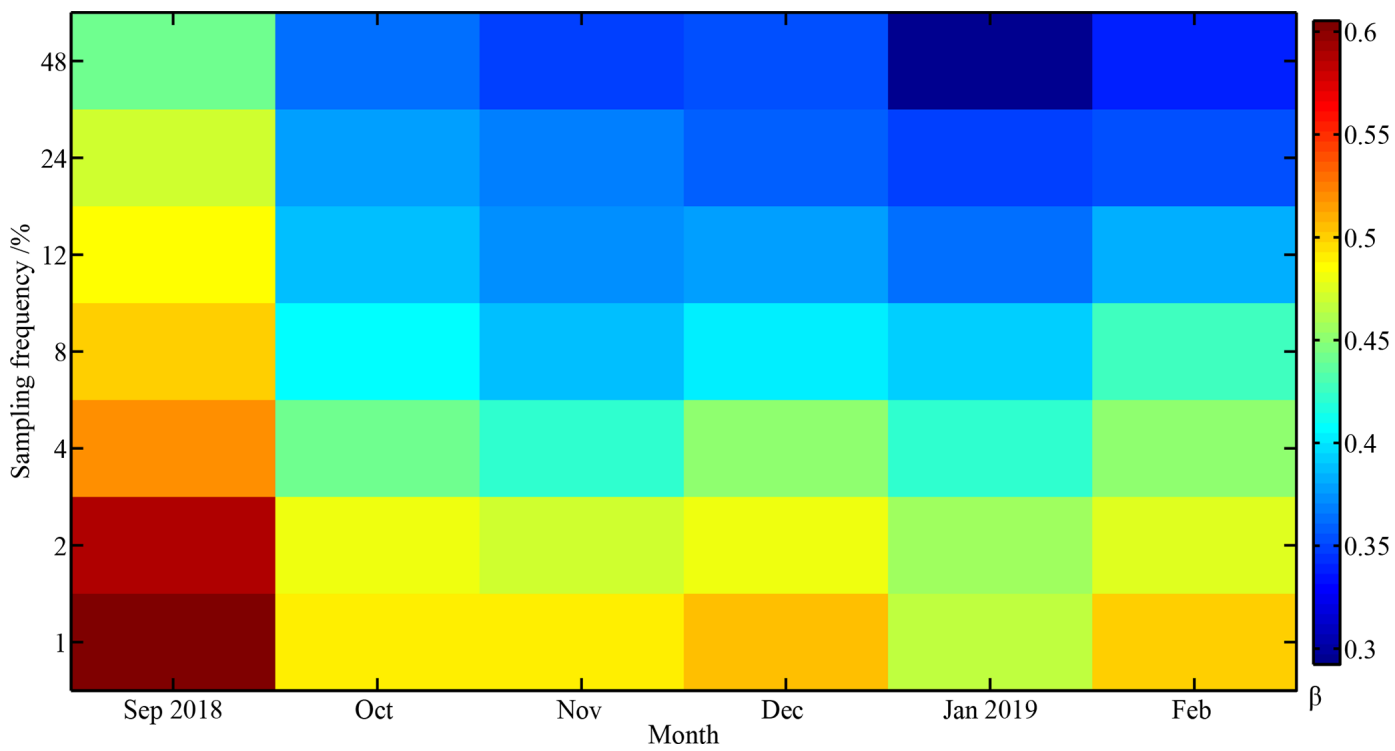

Figure 13. Changes in monthly spatial scaling exponent as a function of position data resampling frequency obtained from the CHINARE buoy cluster.

ary 2019, $\beta$ obtained from hourly position data decreased to 0.48 , which is comparable to February $2015(0.43)$ in the northern PAO (Lei et al., 2020b). This suggests that the interannual changes in the spatial scaling of ice deformation during winter are not as large as that in early autumn, which is in line with the evolution of ice thickness (e.g., Kwok and Cunningham, 2008). $\beta$ decreased exponentially with an increase in resampling frequency for all months, which indicates that the spatial scaling would generally be underestimated when using data of coarser resolution. Interpolated 
to $3 \mathrm{~h}, \beta$ was 0.42 and 0.44 in January and February 2019, respectively, which is comparable with the result $(0.40) \mathrm{ob}-$ tained from the southern PAO during March-May (Itkin et al., 2017). The ice growth season generally lasts until MayJune in the PAO (Perovich et al., 2003), which implies that the sea ice consolidation in March-May is comparable to, or even stronger than, that in January-February. Thus, our $\beta$ is essentially consistent with that given by Itkin et al. (2017). Extrapolated to $48 \mathrm{~h}(120 \mathrm{~h})$, our estimated $\beta$ decreased to $0.29(0.25)$ in January and $0.33(0.28)$ in February 2019, respectively, which is comparable to that $(0.20)$ obtained from the estimations using RADARSAT images with temporal resolution of 48-120 h during the freezing season for the panArctic Ocean (Stern and Lindsay, 2009). We further use the seasonal bin to test the sensitivity of the estimation of $\beta$ to the number of samples. Consequentially, the seasonal $\beta$ was estimated at 0.54 and 0.48 for autumn and winter, respectively, which is close to those ( 0.53 and 0.49 ) averaged directly from the monthly values. Therefore, we believe that the monthly segmentation for estimations of $\beta$ is statistically appropriate and can better reveal seasonal changes.

The temporal scaling exponent $\alpha$ also exhibited a strong dependence on the spatial scale, which means a relatively large intermittency of ice deformation can be obtained by fine-scale observations (Fig. 14). Seasonally, the value of $\alpha$ decreased between September and October 2018 because of enhanced consolidation of the ice cover. The value of the space-time coupling coefficient $c$ increased monotonously from 0.034 in autumn to 0.062 in winter, suggesting a gradual enhancement of the brittle rheology of the ice cover. This is consistent with the results derived from RADARSAT images (Stern and Moritz, 2002), which revealed that sea ice deformation is more linear in winter and more clustered and spatially random in summer. The value of $c$ in September 2018 is comparable to that in September $2016(0.03)$. However, it is only about half that in September 2014 (0.06) (Lei et al., 2020a) because of the different ice conditions. The value of $c$ in January-February $2019(0.059-0.062)$ is comparable with the values obtained in January-February 2015 (0.051-0.077) from the northern PAO (Lei et al., 2020b) and the value obtained from the region north of Svalbard in winter and spring (Oikkonen et al., 2017).

The areal localization index denotes the area with the highest $(15 \%)$ deformation. It increased linearly $(P<0.001)$ as the logarithm of the temporal scale increased (Fig. 15), which implies that the localization of ice deformation would be underestimated when using coarser temporal resolution. Seasonally, the areal localization index decreased significantly from September to November 2018, indicating that ice deformation was increasingly localized during the transition from melting to freezing. In the freezing season, ice deformation mainly occurs along linear cracks, leads, and/or ridges, which corresponds to a high localization. During melt season, the ice-deforming zones are in clumps rather than along lines. The spatial distribution of ice deformation rate is more even and amorphous (Stern and Moritz, 2002), which corresponds to a low localization. From November to February, the degree of ice deformation strongly regulated the localization of ice deformation, with the monthly ice deformation rate explaining $96 \%$ of the monthly areal localization index $(P<0.01)$. This means that an extremely high ice deformation can spread over longer distances. The areal localization index for January-February 2019 corresponding to a temporal resolution of $1 \mathrm{~h}$ and a length scale of $10-$ $20 \mathrm{~km}$ was $1.9 \%-2.3 \%$. This is close to values estimated using RADARSAT images at scales of $13-20 \mathrm{~km}(1.6 \%)$ (Marsan et al., 2004) and of $10 \mathrm{~km}(1.5 \%)$ (Stern and Lindsay, 2009), as well as that estimated at a scale of $18 \mathrm{~km}$ using a high-resolution numerical model (2.4\%-2.7\%) (Spreen et al., 2017). We also analyzed other fractional areas accommodating the largest $10 \%$ or $20 \%$ of the ice deformation. Although the adjusted indices would have different magnitudes, their overall seasonal patterns and dependence on the temporal scale are consistent with those using the threshold of $15 \%$. We therefore conclude that the understanding of the ice deformation localization derived from this study is not very sensitive to the selected threshold.

\subsection{Spatial differences in the trends of sea ice loss in the PAO and their implications for sea ice kinematics and deformation}

Sea ice conditions in the melt season have profound effects on sea ice dynamic and thermodynamic processes in the following winters. For example, enhanced divergence of summer sea ice leads to increased absorption of solar radiation by the upper ocean and delays onset of ice growth (e.g., Lei et al., 2020a). As shown in Fig. 16, the long-term decrease in sea ice concentration in the first half of September, when Arctic sea ice extent typically reaches its annual minimum (Comiso et al., 2017), is stronger in the southern and western PAO than in the northern and eastern PAO. The southern and western PAO have become ice free in September during recent years. On the contrary, there is no significant trend in ice concentration in the first half of September along the trajectory of the easternmost buoy (Fig. 16e). This suggests that the melting period is getting longer in the southern and western PAO compared to the northern and eastern PAO. Consequently, the spatial gradient of ice thickness in the PAO, especially during autumn and early winter, will be further enhanced by the delay in sea ice freezing onset in the south and west. A deformation of the ice field in the seasonal ice zone creates unfrozen ice ridges (Salganik et al., 2020). These new ridges, together with the newly formed thin ice in leads, are mechanically vulnerable components of the ice field during the freezing season and predispose the ice field to further deformation under external forces. At the end of the freezing season, the enhanced ice deformation will promote the sea ice breaking up and expand the MIZ northward, which is conducive to the advance of the melt season. Thus, 


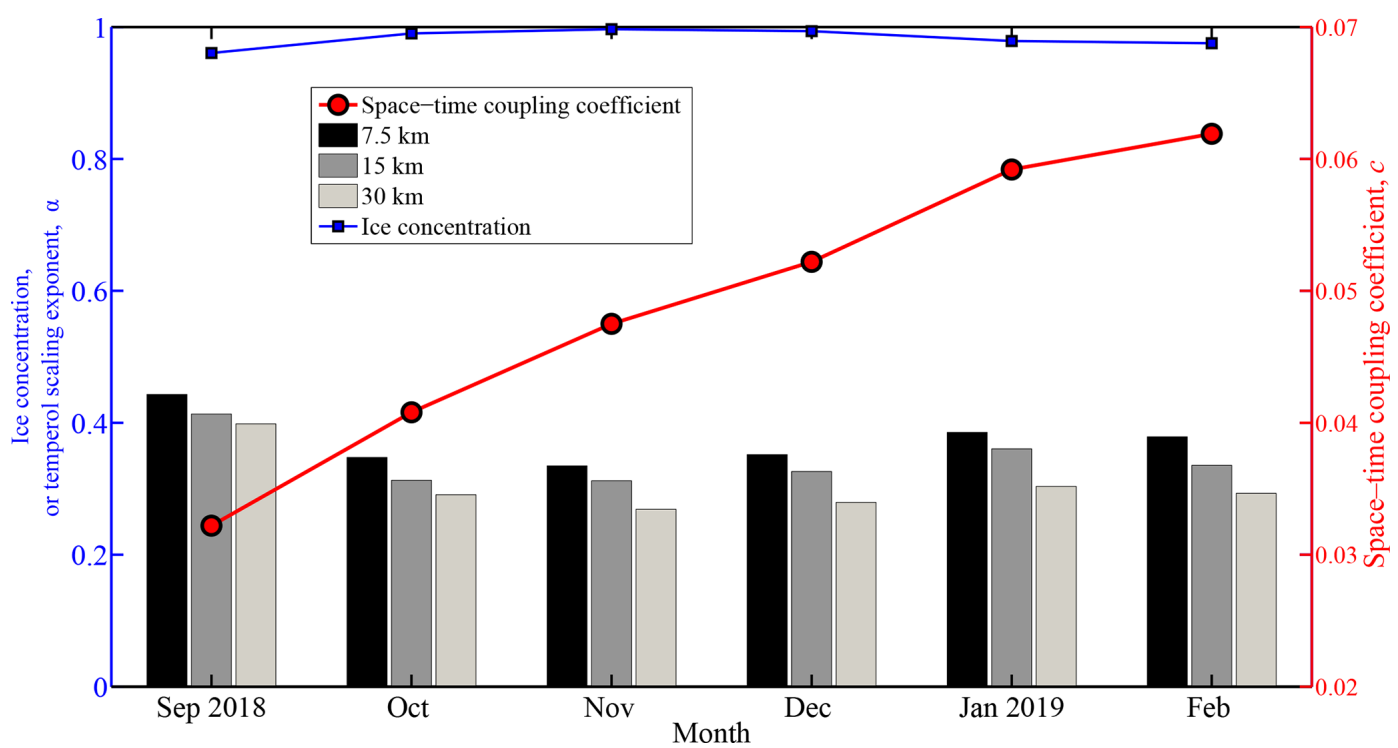

Figure 14. Changes in monthly temporal scaling exponent at various length scales, space-time coupling coefficient, and average ice concentration within the CHINARE buoy cluster.

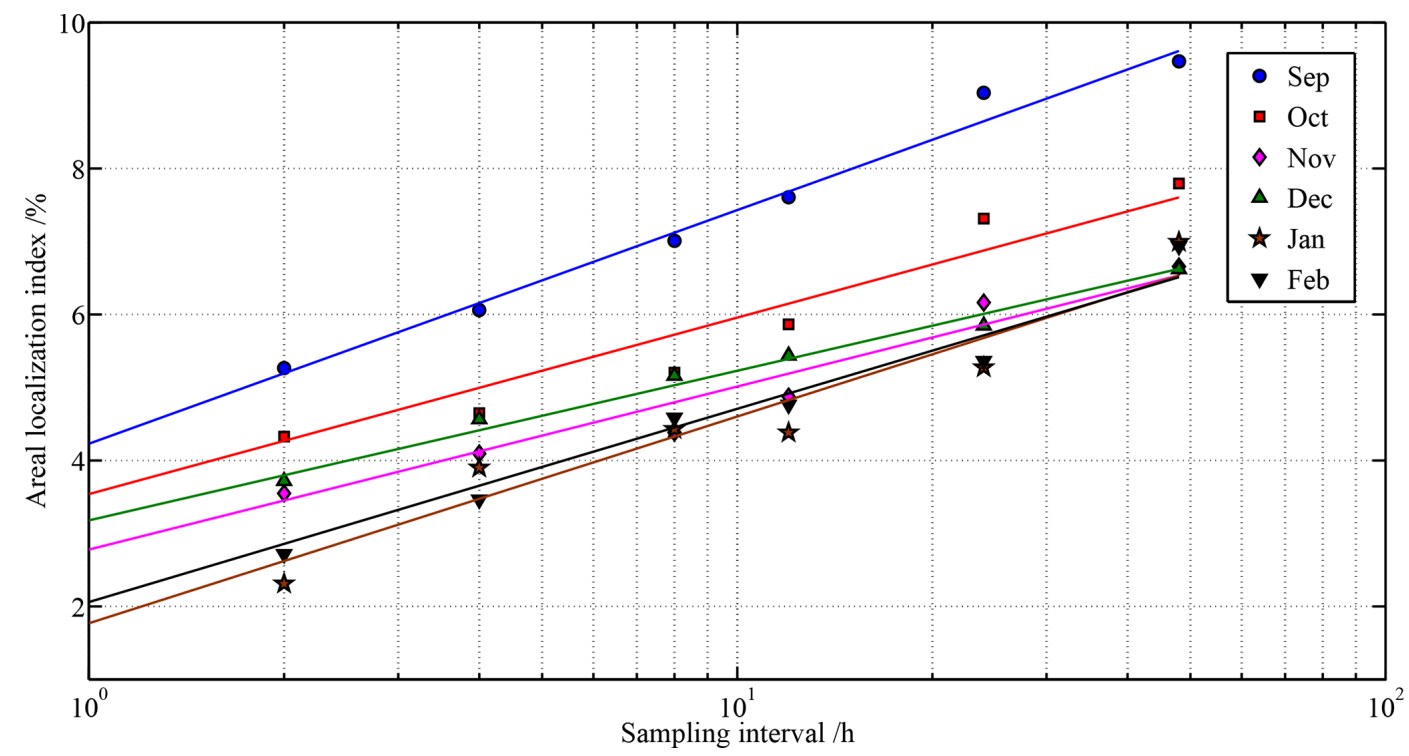

Figure 15. Changes in monthly (September 2018 to February 2019) areal localization index of ice deformation at a scale of 10-20 km as a function of the position data resampling frequency.

the north-south and east-west differences in sea ice kinematics are likely to be more pronounced in the future.

\section{Conclusion and outlook}

High-resolution position data recorded by 32 ice-based drifting buoys in the PAO between August 2018 and February 2019 were analyzed in detail to characterize spatiotemporal variations in sea ice kinematic and deformation properties. During the transition from autumn to winter, ice defor- mation and its response to wind forcing as well as the inertial signal of ice motion gradually weakened. At the same time, space-time coupling of ice deformation was enhanced as the mechanical strength of the ice field increased. The influence of tidal forcing on the quasi-semidiurnal oscillation of ice motion was negligible regardless of the seasons because the buoys drifted over the deep basins beyond the continental shelf. During the freezing season between October 2018 and February 2019, the ice deformation rate in the northern part of the study region was about 2.5 higher compared to in the western part. This difference is likely related to the higher 


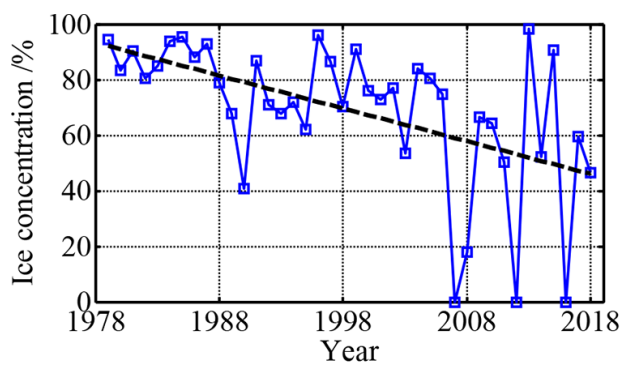

(b) West, Trend: $-1.18 \%$ per year, $R^{2}=0.276, P<0.01$

(c) South, Trend: $-1.95 \%$ per year, $R^{2}=0.482, P<0.001$
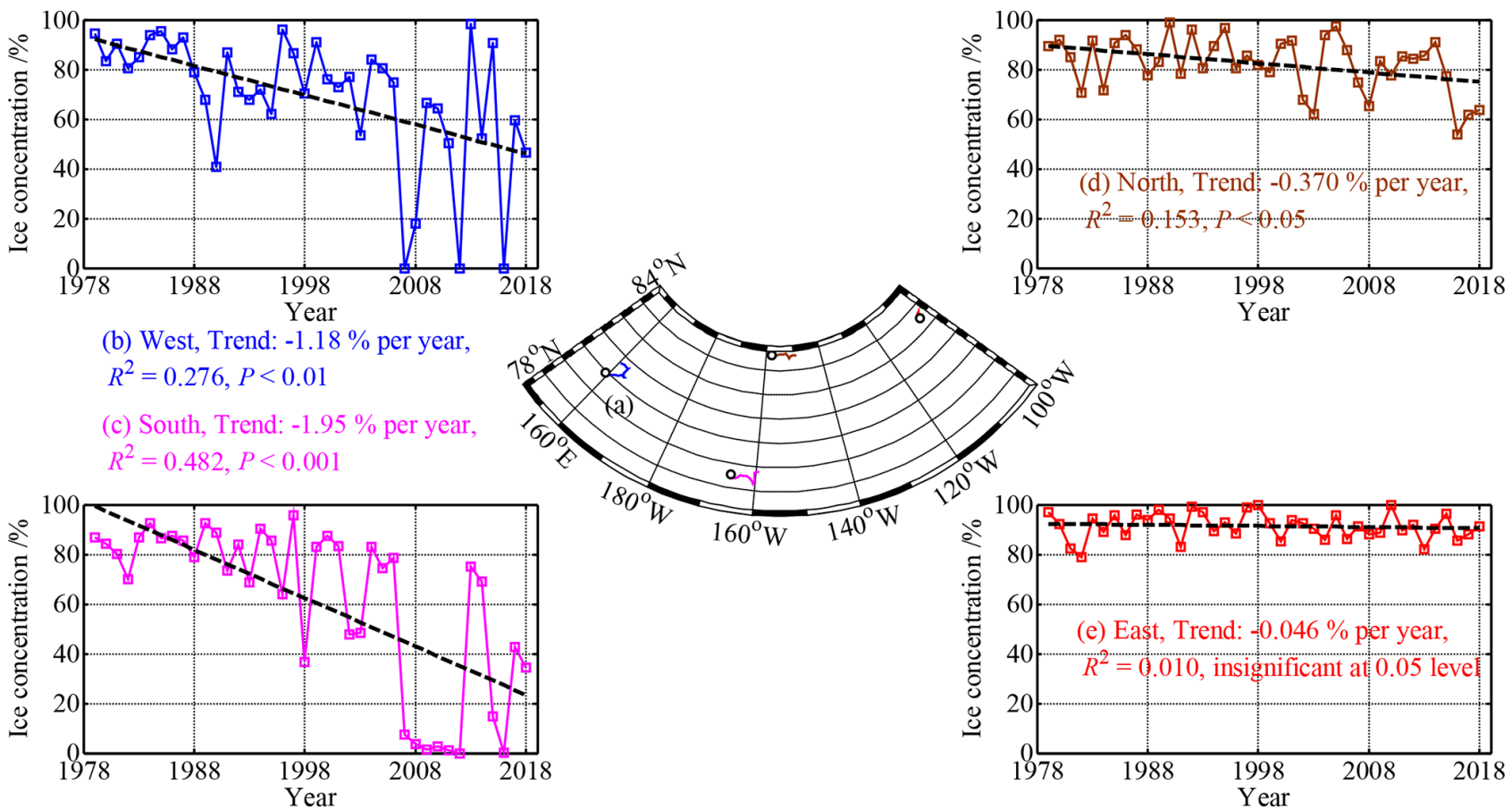

Figure 16. (a) Drift trajectories of the westernmost, southernmost, near-northernmost, and easternmost buoys from 1 to 15 September 2018 ; the northernmost buoy has been omitted because it drifted to the north of $84.5^{\circ} \mathrm{N}$, where SMMR ice concentration data prior to 1987 are unavailable. The trajectory of the westernmost buoy was reconstructed using the NSIDC ice motion product because this buoy was deployed on 15 September 2018. (b-e) Long-term changes in ice concentration along buoy trajectories averaged over 1-15 September, with black lines denoting linear trends.

spatial heterogeneity of the oceanic and atmospheric forcing in the northern part of the study region, which is situated in the core region of the BG. Because of the seasonal change in the large-scale atmospheric circulation pattern, indicated by the enhanced positive phases of the CAI and DA, a significant change in ice drift direction from anticyclonic to cyclonic patterns was observed in late November 2018, leading to temporal increases in both ice deformation rate and its ratio to wind forcing.

The pronounced high intermittence of ice deformation suggests that an episodic opening or closing of the sea ice cover may be undetectable from data with longer sampling intervals, such as remote sensing data with resolutions of 1 or $2 \mathrm{~d}$. Consequently, fluxes of heat (e.g., Heil and Hibler, 2002) or particles and gases (e.g., Held et al., 2011) released from these openings in the PIZ into the atmosphere would be underestimated if they are derived from such data. The dependence of the ratio of ice speed to wind speed on resampling frequency also suggests that the temporal resolution should be considered carefully when using reanalyzed wind data to parameterize or simulate sea ice drift. From a spatial perspective, our results reveal that the intermittence of ice deformation is underestimated at longer scales. This is consistent with results from numerical models, which indicate that the most extreme deformation events may be absent in the output of models with lower spatial resolution (Rampal et al., 2019). This emphasizes the need for high-resolution sea ice dynamic models (e.g., Hutter and Losch, 2020) to reproduce linear kinematic features of ice deformation.

The response of ice kinematics to wind and inertia forcing was stronger in the south and west compared to the north and east of the study region, which is partly associated with the spatial heterogeneity of ice conditions inherited from previous seasons. During the transition from autumn to winter, the north-south and east-west gradients in the IWSR and the inertial component of ice motion gradually decreased and even disappeared entirely, which is in line with the seasonal evolution of ice concentration and thickness. The spatial heterogeneity in autumn ice conditions is likely to be amplified with an increased loss of summer sea ice cover in the southern and western PAO, which is expected to further enhance the eastwest and north-south differences in sea ice kinematics.

We conclude this study by highlighting some of the most important knowledge gaps related to sea ice kinematics and deformation in the Arctic Ocean, not necessarily limited to the PAO, and how they can be addressed in the future. First, the spatiotemporal scale effects of ice deformation in this study were derived based on data recorded by buoys distributed over spatial scales of $5-40 \mathrm{~km}$. In order to assess whether the results of the present study are also representative for a much larger scale, observations by a much wider and denser buoy array, ideally combined with high-resolution 
ship-based radar and satellite remote sensing data, as well as the support of numerical models, are needed. Second, we only examined atmospheric influences on sea ice kinematics and deformation. The ocean also plays an important role in ice drift and deformation, especially on mesoscales, greatly enhancing ice motion nonuniformity and ice deformation (e.g., Zhang et al., 1999). In the PAO, mesoscale eddies prevail over the shelf break and the Northwind and Alpha-Mendeleyev ridges (e.g., Zhang et al., 1999; Zhao et al., 2016). To assess the influence of mesoscale oceanic eddies on ice deformation, observations from ice-drifter arrays are insufficient, highlighting the need for a complementary deployment of ocean-profiler arrays. Third, deformation of sea ice creates ample opportunity for increased sea ice biological activities. Irradiance and nutrients, the two major limiting agents for biological growth in the sea ice realm (Ackley and Sullivan, 1994), are strongly impacted by sea ice deformation. For example, pressure ridges generally have large semi-enclosed chambers, which can provide more nutrients for biological activity (Ackley and Sullivan, 1994; Geiger and Perovich, 2008). Sea ice deformation would also increase ice surface roughness, which in turn increases the potential of melt pond formation in early summer (e.g., Perovich and Polashenski, 2012). The formation of ponds leads to an increase in the transmission of irradiance through the ice cover and promotes the biological growth (e.g., Nicolaus et al., 2012). In order to better understand the linkages between sea ice dynamical and biological processes, more joint observations are urgently needed.

In September 2019, the international Multidisciplinary drifting Observatory for the Study of Arctic Climate (MOSAiC) drift experiment (2019-2020) was launched in the region north of the Laptev Sea (Krumpen et al., 2020), which is to the west of the deployment region of the TICE buoy cluster. The ice thickness around the MOSAiC ice station was much lower than that in the areas of the buoy clusters included in this study (Krumpen et al., 2020). Frequent sea ice breakup events have been reported around the MOSAiC ice camp during the drift. An integral part of MOSAiC was the deployment of a large distributed network of icebased drifting buoys of various types surrounding the main ice camp. Supported by a wealth of multi-disciplinary in situ data, satellite remote sensing data, and numerical model setups, MOSAiC has the potential to properly address most of the aspects outlined above. At the same time, data and results from the present study can be used as a proxy baseline for comparing and investigating deformation of the MOSAiC ice pack.

Data availability. The CHINARE buoy data are archived in the National Arctic and Antarctic Data Center of China at https://www.chinare.org.cn/metadata/ 53de02c5-4524-4be4-b7bb-b56386f1341c (last access: 10 January 2021, https://doi.org/10.11856/NNS.D.2020.038.v0,
Lei, 2018). The TICE SIMBA GPS data (https://doi.org/10.1594/PANGAEA.927592; Hoppmann et al., 2021) and snow buoy data (https://doi.org/10.1594/PANGAEA.927561; Nicolaus et al., 2021, and https://doi.org/10.1594/PANGAEA.905725; Belter et al., 2019) are available in PANGAEA. The IABP buoy data are archived at http://iabp.apl.washington.edu/index.html (last access: 10 March 2020).

Author contributions. RL is responsible for project coordination and paper writing. $\mathrm{MH}, \mathrm{BC}, \mathrm{GZ}$, and DG undertook the processing and analysis of the buoy data and interpretation of results. RL, WY, and HJB deployed the buoys. The buoy data were provided by $\mathrm{RL}, \mathrm{MH}$, and $\mathrm{BC}$. The atmospheric circulation index was calculated by QC. All authors commented on the manuscript.

Competing interests. The authors declare that they have no conflict of interest.

Acknowledgements. We are most grateful to the Chinese Arctic and Antarctic Administration and the Alfred Wegener Institute for their logistical and financial support of the cruises of CHINARE and TICE, respectively. We thank the captains, crews, and science parties of the R/V Xue Long and the Akademik Tryoshnikov, especially cruise leaders Zexun Wei and Benjamin Rabe, for their incredible support during the expeditions. The AMSR2 passive microwave ice concentrations were provided by the University of Bremen. The SMMR and SSMIS ice concentration and ice motion products and the monthly Arctic sea ice index were provided by the NSIDC. The ERA-Interim reanalysis was obtained from the ECMWF. Monthly sea level pressure is obtained from the NCEP/NCAR reanalysis I dataset. We are very grateful to the two anonymous reviewers and the responsible editor Ted Maksym for their comments, which have greatly improved our paper.

Financial support. This research has been supported by the National Key Research and Development Program (grant nos. 2016YFC1400303, 2018YFA0605903, and 2016YFC1401800), the National Natural Science Foundation of China (grant nos. 41722605 and 41976219), the European Union's Horizon 2020 research and innovation program (INTAROS (grant no. 727890)), the Academy of Finland (grant no. 317999), and the Alfred Wegener Institute (FRAM and ACROSS).

Review statement. This paper was edited by Ted Maksym and reviewed by two anonymous referees.

\section{References}

Ackley, S. F. and Sullivan, C. W.: Physical controls on the development and characteristics of Antarctic sea ice biological commu- 
nities - a review and synthesis, Deep-Sea Res., 41, 1583-1604, 1994.

Alam, A. and Curry, J. A.: Evolution of new ice and turbulent fluxes over freezing winter leads, J. Geophys. Res.-Oceans, 103, 15783-15802, 1998.

Armitage, T. W. K., Bacon, S., Ridout, A. L., Petty, A. A., Wolbach, S., and Tsamados, M.: Arctic Ocean surface geostrophic circulation 2003-2014, The Cryosphere, 11, 17671780, https://doi.org/10.5194/tc-11-1767-2017, 2017.

Assmy, P., Fernández-Méndez, M., Duarte, P., Meyer, A., Randelhoff, A., Mundy, C. J., Olsen, L. M., Kauko, H. M., Bailey, A., Chierici, M., Cohen, L., Doulgeris, A. P., Ehn, J. K., Fransson, A., Gerland, S., Hop, H., Hudson, S. R., Hughes, N., Itkin, P., Johnsen, G., King, J. A., Koch, B. P., Koenig, Z., Kwasniewski, S., Laney, S. R., Nicolaus, M., Pavlov, A. K., Polashenski, C. M., Provost, C., Rösel, A., Sandbu, M., Spreen, G., Smedsrud, L. H., Sundfjord, A., Taskjelle, T., Tatarek A., Wiktor J., Wagner, P. M., Wold, A., Steen, H., and Granskog, M. A.: Leads in Arctic pack ice enable early phytoplankton blooms below snow-covered sea ice, Sci. Rep., 7, 40850, https://doi.org/10.1038/srep40850, 2017.

Belter, H. J., Hummel, S., Hansen, M. L. S., and Nicolaus, M.: Snow height on sea ice and sea ice drift from autonomous measurements from buoy 2018S76, deployed during AKADEMIK TRYOSHNIKOV cruise TRANSDRIFT XXIV (TICE), Alfred Wegener Institute, Helmholtz Centre for Polar and Marine Research, Bremerhaven, PANGAEA, https://doi.org/10.1594/PANGAEA.905725, 2019.

Bi, H., Yang, Q., Liang, X., Zhang, L., Wang, Y., Liang, Y., and Huang, H.: Contributions of advection and melting processes to the decline in sea ice in the Pacific sector of the Arctic Ocean, The Cryosphere, 13, 1423-1439, https://doi.org/10.5194/tc-131423-2019, 2019.

Comiso, J. C., Meier, W. N., and Gersten, R.: Variability and trends in the Arctic sea ice cover: results from different techniques, J. Geophys. Res.-Oceans, 122, 6883-6900, https://doi.org/10.1002/2017JC012768, 2017.

Dee, D. P., Uppala, S. M., Simmons, A. J., Berrisford, P., Poli, P., Kobayashi, S., Andrae, U., Balmaseda, M. A., Balsamo, G., Bauer, P., Bechtold, P., Beljaars, A. C. M., Berg, L., Bidlot, J., Bormann, N., Delsol, C., Dragani, R., Fuentes, M., Geer, A. J., Haimberger, L., Healy, S. B., Hersbach, H., Hólm, E. V., Isaksen, L., Kållberg, P., Köhler, M., Matricardi, M., McNally, A. P., Monge-Sanz, B. M., Morcrette, J.-J., Park, B.-K., Peubey, C., Rosnay, P., Tavolato, C., Thépaut, J.-N., and Vitart, F.: The ERA-interim reanalysis: configuration and performance of the data assimilation system, Q. J. Roy. Meteor. Soc., 137, 553-597, https://doi.org/10.1002/qj.828, 2011.

Ding, Q., Schweiger, A., L'Heureux, M., Battisti, D. S., Po-Chedley, S., Johnson, N. C., Blanchard-Wrigglesworth, E., Harnos, K., Zhang, Q., Eastman, R., and Steig, E. J.: Influence of highlatitude atmospheric circulation changes on summertime Arctic sea ice, Nat. Clim. Change, 7, 289-295, 2017.

Fernández-Méndez, M., Olsen, L. M., Kauko, H. M., Meyer, A., Rösel, A., Merkouriadi, I., Mundy, C. J., Ehn, J. K., Johansson, A. M., Wagner, P. M., Ervik, A., Sorrell, B. K., Duarte, P., Wold, A., Hop, H., and Assmy, P.: Algal hot spots in a changing Arctic Ocean: sea-ice ridges and the snow-ice interface, Front. Mar. Sci., 5, 75, https://doi.org/10.3389/fmars.2018.00075, 2018.
Fetterer, F., Knowles, K., Meier, W. N., Savoie, M., and Windnagel, A. K.: Updated daily sea ice index, version 3, sea ice concentration, Boulder, Colorado, USA, NSIDC: National Snow and Ice Data Center, https://doi.org/10.7265/N5K072F8, 2017.

Geiger, C. A. and Perovich, D. K.: Springtime ice motion in the western Antarctic Peninsula region, Deep-Sea Res., 55, 338-350, 2008.

Gimbert, F., Marsan, D., Weiss, J., Jourdain, N. C., and Barnier, B.: Sea ice inertial oscillations in the Arctic Basin, The Cryosphere, 6, 1187-1201, https://doi.org/10.5194/tc-6-1187-2012, 2012.

Haller, M., Brümmer, B., and Müller, G.: Atmosphere-ice forcing in the transpolar drift stream: results from the DAMOCLES ice-buoy campaigns 2007-2009, The Cryosphere, 8, 275-288, https://doi.org/10.5194/tc-8-275-2014, 2014.

Heil, P. and Hibler III, W. D.: Modeling the high-frequency component of Arctic sea ice drift and deformation, J. Phys. Oceanogr., 32, 3039-3057, 2002.

Held, A., Brooks, I. M., Leck, C., and Tjernström, M.: On the potential contribution of open lead particle emissions to the central Arctic aerosol concentration, Atmos. Chem. Phys., 11, 30933105, https://doi.org/10.5194/acp-11-3093-2011, 2011.

Herman, A. and Glowacki, O.: Variability of sea ice deformation rates in the Arctic and their relationship with basin-scale wind forcing, The Cryosphere, 6, 1553-1559, https://doi.org/10.5194/tc-6-1553-2012, 2012.

Hoppmann, M., Belter, H. J., and Riemann-Campe, K.: GPS data of selected drifting buoys deployed in the Pacific sector of the Arctic Ocean during the TRANSDRIFT/TICE/NABOS expedition in summer 2018, Alfred Wegener Institute, Helmholtz Centre for Polar and Marine Research, Bremerhaven, PANGAEA, https://doi.org/10.1594/PANGAEA.927592, 2021.

Hutchings, J. K. and Hibler III, W. D.: Small-scale sea ice deformation in the Beaufort Sea seasonal ice zone, J. Geophys. Res., 113, C08032, https://doi.org/10.1029/2006JC003971, 2008.

Hutchings, J. K., Roberts, A., Geiger, C. A., and Richter-Menge, J.: Spatial and temporal characterization of sea-ice deformation, Ann. Glaciol., 52, 360-368, 2011.

Hutchings, J. K., Heil, P., Steer, A., and Hibler III, W. D.: Subsynoptic scale spatial variability of sea ice deformation in the western Weddell Sea during early summer, J. Geophys. Res., 117, C01002, https://doi.org/10.1029/2011JC006961, 2012.

Hutchings, J. K., Roberts, A., Geiger, C. A., and Richter-Menge, J.: Corrigendum: Spatial and temporal characterization of sea-ice deformation, J. Glaciol., 64, 343-346, 2018.

Hutter, N. and Losch, M.: Feature-based comparison of sea ice deformation in lead-permitting sea ice simulations, The Cryosphere, 14, 93-113, https://doi.org/10.5194/tc-14-93-2020, 2020.

Hutter, N., Losch, M., and Menemenlis, D.: Scaling properties of arctic sea ice deformation in a high-resolution viscous-plastic sea ice model and in satellite observations, J. Geophys. Res.-Oceans, 123, 672-687, https://doi.org/10.1002/2017JC013119, 2018.

Itkin, P., Spreen, G., Cheng, B., Doble, M., Girard-Ardhuin, F., Haapala, J., Hughes, N., Kaleschke, L., Nicolaus, M., and Wilkinson, J.: Thin ice and storms: Sea ice deformation from buoy arrays deployed during N-ICE2015, J. Geophys. Res., 122, 4661-4674, https://doi.org/10.1002/2016JC012403, 2017.

Itkin, P., Spreen, G., Hvidegaard, S. M., Skourup, H., Wilkinson, J., Gerland, S., and Granskog, M. A.: Contribution of 
deformation to sea ice mass balance: A case study from an N-ICE2015 storm, Geophys. Res. Lett., 45, 789-796, https://doi.org/10.1002/2017GL076056, 2018.

Krumpen, T., Birrien, F., Kauker, F., Rackow, T., von Albedyll, L., Angelopoulos, M., Belter, H. J., Bessonov, V., Damm, E., Dethloff, K., Haapala, J., Haas, C., Harris, C., Hendricks, S., Hoelemann, J., Hoppmann, M., Kaleschke, L., Karcher, M., Kolabutin, N., Lei, R., Lenz, J., Morgenstern, A., Nicolaus, M., Nixdorf, U., Petrovsky, T., Rabe, B., Rabenstein, L., Rex, M., Ricker, R., Rohde, J., Shimanchuk, E., Singha, S., Smolyanitsky, V., Sokolov, V., Stanton, T., Timofeeva, A., Tsamados, M., and Watkins, D.: The MOSAiC ice floe: sediment-laden survivor from the Siberian shelf, The Cryosphere, 14, 2173-2187, https://doi.org/10.5194/tc-14-2173-2020, 2020.

Kwok, R.: Contrasts in sea ice deformation and production in the Arctic seasonal and perennial ice zones, J. Geophys. Res., 111, C11S22, https://doi.org/10.1029/2005JC003246, 2006.

Kwok, R. and Cunningham, G. F.: ICESat over Arctic sea ice: Estimation of snow depth and ice thickness, J. Geophys. Res., 113, C08010, https://doi.org/10.1029/2008JC004753, 2008.

Lammert, A., Brümmer, B., and Kaleschke, L.: Observation of cyclone-induced inertial sea-ice oscillation in Fram Strait, Geophys. Res. Lett., 36, L10503, https://doi.org/10.1029/2009GL037197, 2009.

Lei, R.: Position data measured by ice-based buoys deployed during the CHINARE Aritic cruise, National Arctic and Antarctic Data Center, 2020, https://doi.org/10.11856/NNS.D.2020.038.v0, 2018.

Lei, R., Tian-Kunze, X., Leppäranta, M., Wang, J., Kaleschke, L., and Zhang Z.: Changes in summer sea ice, albedo, and portioning of surface solar radiation in the Pacific sector of Arctic Ocean during 1982-2009, J. Geophys. Res. Oceans, 121, 5470-5486, https://doi.org/10.1002/2016JC011831, 2016.

Lei, R., Gui, D., Hutchings, J. K., Wang, J., and Pang, X.: Backward and forward drift trajectories of sea ice in the northwestern Arctic Ocean in response to changing atmospheric circulation, Int. J. Climatol., 39, 1-20, https://doi.org/10.1002/joc.6080, 2019.

Lei, R., Gui, D., Heil, P., Hutchings, J. K., and Ding, M.: Comparisons of sea ice motion and deformation, and their responses to ice conditions and cyclonic activity in the western Arctic Ocean between two summers, Cold Reg. Sci. Technol., 170, 102925, https://doi.org/10.1016/j.coldregions.2019.102925, 2020a.

Lei, R., Gui, D., Hutchings, J. K., Heil, P., and Li, N.: Annual cycles of sea ice motion and deformation derived from buoy measurements in the western Arctic Ocean over two ice seasons, J. Geophys. Res., 125, e2019JC015310, https://doi.org/10.1029/2019JC015310, 2020b.

Lewis, J. K. and Richter-Menge, J. A.: Motion-induced stresses in pack ice, J. Geophys. Res., 103, 21831-21843, https://doi.org/10.1029/98JC01262, 1998.

Lindell, D. B. and Long, D. G.: Multiyear Arctic ice classification using ASCAT and SSMIS, Remote Sens., 8, 294, https://doi.org/10.3390/rs8040294, 2016.

Lukovich, J. V., Babb, D. G., and Barber, D. G.: On the scaling laws derived from ice beacon trajectories in the southern Beaufort Sea during the International Polar Year-Circumpolar Flaw Lead study, 2007-2008, J. Geophys. Res., 116, C00G07, https://doi.org/10.1029/2011JC007049, 2011.
Marsan, D. and Weiss, J.: Space/time coupling in brittle deformation at geophysical scales, Earth Planet. Sci. Lett., 296, 353-359, 2010.

Marsan, D., Stern, H., Lindsay, R., and Weiss, J.: Scale dependence and localization of the deformation of Arctic sea ice, Phys. Res. Lett., 93, 178501, https://doi.org/10.1103/PhysRevLett.93.178501, 2004.

Moore, G. W. K., Schweiger, A., Zhang, J., and Steele, M.: Collapse of the 2017 winter Beaufort High: A response to thinning sea ice?, Geophys. Res. Lett., 45, 2860-2869, https://doi.org/10.1002/2017GL076446, 2018.

Nicolaus, M., Katlein, C., Maslanik, J., and Hendricks, S.: Changes in Arctic sea ice result in increasing light transmittance and absorption, Geophys. Res. Lett., 39, L24501, https://doi.org/10.1029/2012GL053738, 2012.

Nicolaus, M., Belter, H. J., Hummel, S., Hansen, M. L. S., Rabe, B., Tippenhauer, S., Vredenborg, M., and Hoppmann, M.: Snow height on sea ice and sea ice drift from autonomous measurements from buoy 2018S75, deployed during AKADEMIK TRYOSHNIKOV cruise TRANSDRIFT XXIV/TICE, Alfred Wegener Institute, Helmholtz Centre for Polar and Marine Research, Bremerhaven, PANGAEA, https://doi.org/10.1594/PANGAEA.927561, 2021.

Oikkonen, A., Haapala, J., Lensu, M., Karvonen, J., and Itkin, P.: Small-scale sea ice deformation during N-ICE2015: From compact pack ice to marginal ice zone, J. Geophys. Res.-Oceans, 122, 5105-5120, https://doi.org/10.1002/2016JC012387, 2017.

Perovich, D., Meier, W., Tschudi, M., Farrell, S., Hendricks, S., Gerland, S., Kaleschke, L., Ricker, R., Tian-Kunze, X., Webster, M., and Wood, K.: Sea ice. Arctic report card 2019, 2634, available at: http://www.arctic.noaa.gov/Report-Card (last access: 10 April 2020), 2019.

Perovich, D. K. and Polashenski, C.: Albedo evolution of seasonal Arctic sea ice, Geophys. Res. Lett., 39, L08501, https://doi.org/10.1029/2012GL051432, 2012.

Perovich, D. K., Grenfell, T. C., Richter-Menge, J. A., Light, B., Tucker III, W. B., and Eicken, H.: Thin and thinner: sea ice mass balance measurements during SHEBA, J. Geophys. Res., 108, 8050, https://doi.org/10.1029/2001JC001079, 2003.

Proshutinsky, A., Krishfield, R., Timmermans, M. L., Toole, J., Carmack, E., McLaughlin, F., Williams, W. J., Zimmermann, S., Itoh, M., and Shimada, K.: Beaufort Gyre freshwater reservoir: State and variability from observations, J. Geophys. Res., 114, C00A10, https://doi.org/10.1029/2008JC005104, 2009.

Rampal, P., Weiss, J., Marsan, D., Lindsay, R., and Stern, H.: Scaling properties of sea ice deformation from buoy dispersion analysis, J. Geophys. Res., 113, C03002, https://doi.org/10.1029/2007JC004143, 2008.

Rampal, P., Dansereau, V., Olason, E., Bouillon, S., Williams, T., Korosov, A., and Samaké, A.: On the multi-fractal scaling properties of sea ice deformation, The Cryosphere, 13, 2457-2474, https://doi.org/10.5194/tc-13-2457-2019, 2019.

Salganik, E., Høyland, K. V., and Maus, S.: Consolidation of fresh ice ridges for different scales, Cold Reg. Sci. Technol., 171, 102959, https://doi.org/10.1016/j.coldregions.2019.102959, 2020.

Screen, J. A. and Simmonds, I.: Increasing fall-winter energy loss from the Arctic Ocean and its role in Arctic 
temperature amplification, Geophys. Res. Lett., 37, L16707, https://doi.org/10.1029/2010GL044136, 2010.

Serreze, M. C. and Meier, W. N.: The Arctic's sea ice cover: trends, variability, predictability, and comparisons to the Antarctic, Ann. N.Y. Acad. Sci., 1436, 36-53, https://doi.org/10.1111/nyas.13856, 2018.

Spreen, G., Kaleschke, L., and Heygster, G.: Sea ice remote sensing using AMSR-E $89 \mathrm{GHz}$ channels, J. Geophys. Res., 113, C02S03, https://doi.org/10.1029/2005JC003384, 2008.

Spreen, G., Kwok, R., and Menemenlis, D.: Trends in Arctic sea ice drift and role of wind forcing: 1992-2009, Geophys. Res. Lett., 38, L19501, https://doi.org/10.1029/2011GL048970, 2011.

Spreen, G., Kwok, R., Menemenlis, D., and Nguyen, A. T.: Sea-ice deformation in a coupled ocean-sea-ice model and in satellite remote sensing data, The Cryosphere, 11, 1553-1573, https://doi.org/10.5194/tc-11-1553-2017, 2017.

Steele, M. and Dickinson, S.: The phenology of Arctic Ocean surface warming, J. Geophys. Res.-Oceans, 121, 6847-6861, https://doi.org/10.1002/2016JC012089, 2016.

Stern, H. L. and Lindsay, R. W.: Spatial scaling of Arctic sea ice deformation, J. Geophys. Res., 114, C10017, https://doi.org/10.1029/2009JC005380, 2009.

Stern, H. L. and Moritz, R. E.: Sea ice kinematics and surface properties from RADARSAT synthetic aperture radar during the SHEBA drift, J. Geophys. Res., 107, 8028, https://doi.org/10.1029/2000JC000472, 2002.

Strong, C. and Rigor, I. G.: Arctic marginal ice zone trending wider in summer and narrower in winter, Geophys. Res. Lett., 40, 4864-4868, https://doi.org/10.1002/grl.50928, 2013.
Tschudi, M., Meier, W. N., Stewart, J. S., Fowler, C., and Maslanik, J.: Polar Pathfinder Daily $25 \mathrm{~km}$ EASE-Grid Sea Ice Motion Vectors, Version 4, Boulder, CA, USA, NASA National Snow and Ice Data Center Distributed Active Archive Center, https://doi.org/10.5067/INAWUWO7QH7B, 2019.

Tschudi, M. A., Meier, W. N., and Stewart, J. S.: An enhancement to sea ice motion and age products at the National Snow and Ice Data Center (NSIDC), The Cryosphere, 14, 1519-1536, https://doi.org/10.5194/tc-14-1519-2020, 2020.

Vihma, T., Tisler, P., and Uotila, P.: Atmospheric forcing on the drift of Arctic sea ice in 1989-2009, Geophys. Res. Lett., 39, L02501, https://doi.org/10.1029/2011GL050118, 2012.

Wang, J., Zhang, J., Watanabe, E., Mizobata, K., Ikeda, M., Walsh, J. E., Bai, X., and Wu, B.: Is the Dipole Anomaly a major driver to record lows in the Arctic sea ice extent?, Geophys. Res. Lett., 36, L05706, https://doi.org/10.1029/2008GL036706, 2009.

Woodgate, R. A., Weingartner, T. J., and Lindsay, R.: Observed increases in Bering Strait oceanic fluxes from the Pacific to the Arctic from 2001 to 2011 and their impacts on the Arctic Ocean water column, Geophys. Res. Lett., 39, L24603, https://doi.org/10.1029/2012GL054092, 2012.

Zhang, Y., Maslowski, W., and Semtner, A. J.: Impact of mesoscale ocean currents on sea ice in high-resolution Arctic ice and ocean simulations, J. Geophys. Res., 104, 18409-18429, https://doi.org/10.1029/1999JC900158, 1999.

Zhao, M., Timmermans, M.-L., Cole, S., Krishfield, R., and Toole, J.: Evolution of the eddy field in the Arctic Ocean's Canada Basin, 2005-2015, Geophys. Res. Lett., 43, 8106-8114, https://doi.org/10.1002/2016GL069671, 2016. 